\title{
Colloidal Oxide Perovskite Nanocrystals: From Synthesis to Application
}

\author{
Pedro López-Domínguez and Isabel Van Driessche*
}

\begin{abstract}
Nanocrystals (NCs) are complex systems that offer a superior level of detailed engineering at the atomic level. The large number of novel and revolutionary applications have made nanocrystals of special interest. In particular oxide perovskites are one of the most widely investigated family of materials in solid-state chemistry, especially for their ferroelectric and superconducting properties. In addition to these well-known properties, perovskites show good electrical conductivity (close to metals), ion conductivity and mixed ionic-electronic conductivity. In that sense, controlled synthesis of nanomaterials with special care over size and shape are essential in many fields of science and technology. Although it is well-known that physical methods deliver excellent quality nanomaterials, their high production cost has increased the interest to more affordable alternative chemical processes. In this review, we focus on the preparation of sub-10 nm oxide perovskite nanocrystals and the main strategies used to control the final properties of the obtained products. In the second part, we present the methods available for nanocrystal solutions processing together with the most remarkable applications foreseen.
\end{abstract}

Keywords: Colloids $\cdot$ Nanocrystals $\cdot$ Oxides $\cdot$ Perovskite $\cdot$ Synthesis

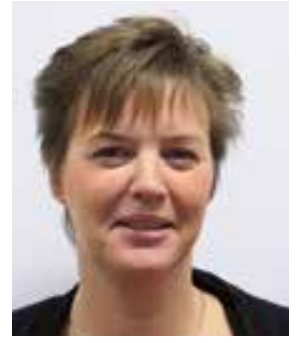

Isabel Van Driessche is professor at Ghent University (Belgium) since 2004 and Dean of the faculty of Sciences since 2018. Together with Prof. De Buysser, she leads the research group SCRiPTS, (scripts. ugent.be), having activities in the broad field of solid-state chemistry related to the synthesis, properties and applications of inorganic (ceramic) materials, both as bulk, nanomaterials and thin films. She is author of approximately 500 papers (ORCID iD: 0000-00015253-3325), co-inventor of 7 patents and has coordinated about 70 national and international research projects. This includes the coordination of 2 European projects, 'EFECTS' ( 8 partners, 2 $\mathrm{M} €$ ) and 'SynFoNY' (5 partners, $600 \mathrm{k€})$ and co-coordination of 'EUROTAPES' (20 partners, $12 \mathrm{M€}$ ) as task force leader. The research group of SCRiPTS is completed with 3 Post-doc researchers and $8 \mathrm{PhD}$ students covering the following fields of interest: i) Chemical solution deposition (CSD, ink jet printing) of ceramics and metaloxides; ii) Formulation of environmentally friendly based inks of metaloxides. Use of bottom-up chemical synthesis approaches for the synthesis of ceramic nanoparticles/ suspensions; iii) Synthesis of multi-metaloxide nanoparticles.

\section{Introduction}

Nanomaterials have surrounded humanity longer than we were even aware. Advances in characterization techniques have brought a new era of materials 'à la carte'. From $\mathrm{TiO}_{2}$ nanoparticles that protect our skin from harmful UV radiation to the new nanofiber-based FFP2 masks that are helping in the fight against SARS-CoV-2,[1] nanomaterials have penetrated consumer products with great success. Oxide perovskites are a wellestablished family among the metal oxide materials class. The general formula of perovskites is $\mathrm{ABO}_{3}$ (Fig. 1A), and should not be confused with ilmenite and derived structures. Although sharing the same molecular formula, in the ilmenite case the A and B cations are similar in size and occupy an octahedral site, as can be seen in Fig. 1B. In perovskite oxides however, A cations are located at 12-coordinated large sites and B cations at 6-coordinated small sites. Different combinations of charged cations are possible, with $\mathrm{A}^{2+}$ and $\mathrm{B}^{4+}$ as the most common disposition.
A

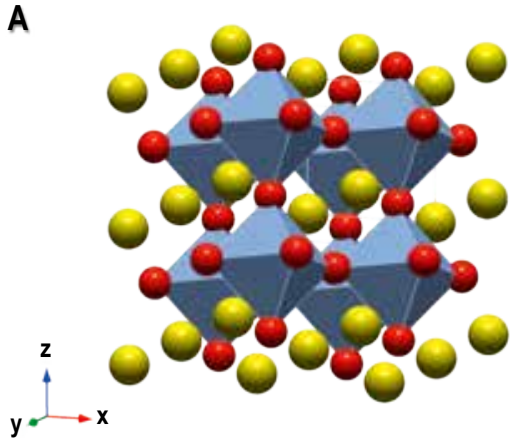

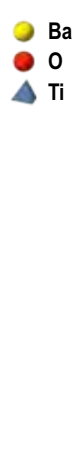

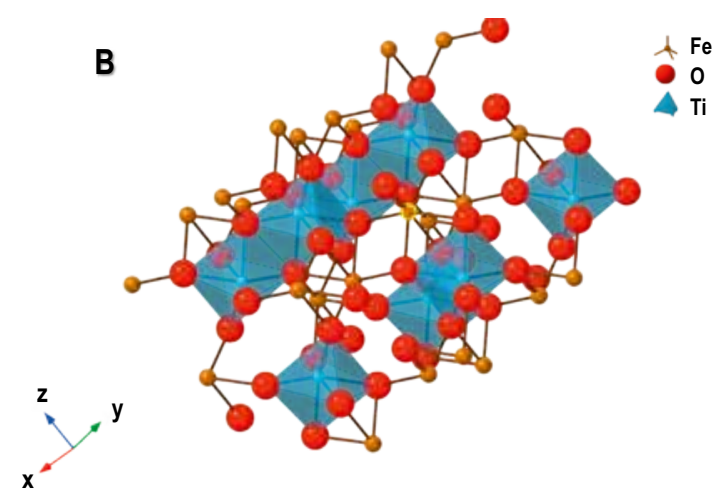

Fig. 1. Schematic illustration of perovskite oxide $\mathrm{BaTiO}_{3}(\mathrm{~A})$ and ilmenite $\mathrm{FeTiO}_{3}$ (B) structures. $3 \mathrm{D}$ graphics obtained with CrystalMaker ${ }^{\circledR} \mathrm{X}$ software (crystalmaker.com). 
Perovskites ideally have a cubic crystal structure (e.g. $\mathrm{BaZrO}_{3}$, $\mathrm{SrTiO}_{3}, \mathrm{BaMnO}_{3}$, etc.). However, due to the vast number of possible combinations, many perovskite oxides have a lower symmetry due to slight distortions in their structure, falling into the category of hexagonal or orthorhombic lattices. ${ }^{[2]}$ The deviation from the ideal perovskite structure can be calculated with the Goldschmidt tolerance factor $(t),{ }^{[3]}$ an empirical index able to predict which structure is preferentially formed. The value is obtained from the ionic radius of the comprised atoms as expressed in Eqn. (1).

$$
t=\frac{r_{A}+r_{B}}{\sqrt{2}\left(r_{B}+r_{X}\right)}
$$

The tolerance factor has been used with great success for structure stability prediction without the use of computational electronic-structure calculations. However, its performance starts to fail when double perovskite oxides $\left(\mathrm{A}_{2} \mathrm{BB}^{\prime} \mathrm{O}_{6}\right)$ are assessed. New versions of the tolerance factor have been developed, successfully proven for single and double perovskite oxide and halides structures. ${ }^{[4]}$ This variety of structure and chemical compositions results in a broad array of properties, including: ferromagnetism, ${ }^{[5]}$ piezoelectricity ${ }^{[6]}$ and ferroelectricity, ${ }^{[7]}$ multiferroics, ${ }^{[8]}$ superconductivity, ${ }^{[9]}$ ion conductivity, ${ }^{[10]}$ catalytic activity ${ }^{[11]}$ and electrode materials. ${ }^{[12]}$ Such properties are strongly dependent on the size, shape, crystallinity and surface composition. For instance, the transition temperature of $\mathrm{BaTiO}_{3}$ from the ferroelectric (tetragonal) to the paraelectric (cubic) phase decreases progressively with the nanocrystal size, due to a decrease on the distortion for titanium atoms in the $\mathrm{TiO}_{6}$ coordination octahedra. There is still not a consensus towards the critical size at which ferroelectricity is suppressed. Therefore, it is of utmost importance to continue developing novel material fabrication strategies to solve technological and fundamental scientific problems. Even though an extensive number of experimental conditions are available, a general methodology for perovskite oxide nanocrystals with fine control over size and shape is still lacking.

In this review, we discuss the leading synthetic methods to obtain sub-10 nm perovskite oxide nanocrystals. We choose to set the boundary at $10 \mathrm{~nm}$ due to the potential of such small nanocrystals as attractive candidates in biomedical applications, ${ }^{[13]}$ artificial pinning centers in superconductors ${ }^{[14]}$ or in photocatalysis..$^{[15]}$ This review tries to present the challenges faced by synthetic chemists when dealing with such small materials. Therefore, the focus lies on strategies capable of both successfully preparing these sub-10 $\mathrm{nm}$ oxide perovskite nanocrystals and stabilizing them into as colloidal dispersions. Although we present different compositions throughout the text, most examples will be from $\mathrm{BaTiO}_{3}$, as it is by far the most studied material. In the second part, we review selected examples of the application of stabilized colloids, giving details about the critical points of colloidal design regarding the final application.

\section{Nanocrystals Synthesis Methods}

Most of the perovskite oxides industrially available nowadays are prepared via conventional solid-state reactions. This implies a high-temperature thermal process (above $1000^{\circ} \mathrm{C}$ ) resulting in polycrystalline materials with poor control over shape and size. ${ }^{[16]}$ Some efforts have been made to reduce crystalline size in a topdown approach, especially by high-energy ball milling ${ }^{[17]}$ or by using a surface-active etching salt. ${ }^{[18]}$ Although this approach is simple and convenient due to the readily available technology, the resulting nanopowders are well above the $10 \mathrm{~nm}$ threshold. There is also no procedure available for their stabilization into nanoparticle solutions. For advanced applications, controlled synthetic routes with special care of shape, size and size distribution become fundamental. It is here that chemical processes gain importance as the most flexible approach to obtaining high-quality nanocrystals (NCs) with controlled morphology and crystal structure. In the following sections the main synthetic strategies will be discussed, illustrated with representative examples. The examples are also presented in Table 1 for clarity.

\subsection{Hydrothermal and Solvothermal}

Solvothermal and hydrothermal syntheses are an important branch of inorganic chemistry. These techniques have a history of more than 100 years, which started with the synthesis of minerals and extraction of elements. Nowadays, it represents an effective

Table 1. Quick-access table of most representative synthesis examples.

\begin{tabular}{|c|c|c|c|c|c|c|c|c|}
\hline $\begin{array}{l}\text { Synthesis } \\
\text { method }\end{array}$ & Sub-type & Precursor & $\begin{array}{l}\text { Experimental } \\
\text { conditions }\end{array}$ & $\begin{array}{l}\text { Sample } \\
\text { obtained }\end{array}$ & Phase & Controllable & Dispensability & Ref. \\
\hline Hydrothermal & - & $\mathrm{Ba}\left(\mathrm{NO}_{3}\right)_{2}, \mathrm{TiCl}_{3}$ & $\begin{array}{l}140-200^{\circ} \mathrm{C} \\
24 \text { hours }\end{array}$ & $17-20 \mathrm{~nm}$ & $\begin{array}{l}\text { BTO } \\
\text { STO }\end{array}$ & by temperature & non-polar solvents & [24] \\
\hline \multirow[t]{2}{*}{ Solvothermal } & One-phase & $\begin{array}{l}\mathrm{Ba}(\mathrm{Sr})(\mathrm{OBn})_{\mathrm{x}} \\
\mathrm{Ti}(\mathrm{Zr})\left(\mathrm{O}^{i} \mathrm{Pr}\right)_{4}\end{array}$ & $\begin{array}{l}200-220^{\circ} \mathrm{C} \\
48-72 \text { hours }\end{array}$ & $\begin{array}{l}4-5 \mathrm{~nm} \\
5-10 \mathrm{~nm}\end{array}$ & $\begin{array}{l}\text { BTO } \\
\text { STO }\end{array}$ & - & $\begin{array}{l}\text { O.A.-cyclohexene }{ }^{[32]} \\
\text { MEEAA-EtOH } \\
\text { MEE] } \\
\text { MEAA-PGMEA }^{[105]}\end{array}$ & [27] \\
\hline & Two-phase & $\mathrm{Ba}(\mathrm{OAc})_{2}, \mathrm{Ti}(n-\mathrm{OBu})_{4}$ & $\begin{array}{l}180^{\circ} \mathrm{C} \\
12 \text { hours }\end{array}$ & $3.7 \mathrm{~nm}$ & BTO & $\begin{array}{l}\text { by modifying } \\
\text { exp. conditions }\end{array}$ & $\begin{array}{l}\text { Organic solvents, e.g. } \\
\text { DCM, PhMe }\end{array}$ & {$[34]$} \\
\hline \multirow{4}{*}{ Sol-gel } & $\begin{array}{l}\text { Sol-gel } \\
\text { precipitation }\end{array}$ & $\mathrm{Ba}(\mathrm{OH})_{2}+\mathrm{Ti}(\mathrm{OBu})_{4}$ & $\begin{array}{l}160^{\circ} \mathrm{C} \\
0.25^{-2} \text { hours }\end{array}$ & $2.8 \mathrm{~nm}$ & ВТО & $\begin{array}{l}\text { by solvent } \\
\text { modification }\end{array}$ & $\begin{array}{l}\text { dispersed in the sol, } \\
\mathrm{N}, \mathrm{N}-\mathrm{DMF}^{[77]}\end{array}$ & [37] \\
\hline & Vapor-diffusion & $\mathrm{BaTi}\left[\mathrm{OCH}_{2} \mathrm{CH}\left(\mathrm{CH}_{3}\right) \mathrm{OCH}_{3}\right]_{6}$ & $\begin{array}{l}16^{\circ} \mathrm{C} \\
15^{\text {hours }}\end{array}$ & $5.9 \mathrm{~nm}$ & BTO & - & $\begin{array}{l}\text { EtOH },{ }^{[43]} \text { Phosphonic } \\
\text { acid-PhMe }\end{array}$ & [40] \\
\hline & Hot-injection & $\operatorname{BaTi}\left(\mathrm{O}_{2} \mathrm{CC}_{7} \mathrm{H}_{15}\right)\left[\mathrm{OCH}\left(\mathrm{CH}_{3}\right)_{2}\right]_{5}$ & $\begin{array}{l}100^{\circ} \mathrm{C} \\
48 \text { hours }\end{array}$ & $8.0 \mathrm{~nm}$ & BTO & $\begin{array}{l}\text { by precursor/ } \\
\text { O.A. }{ }^{\mathrm{a}} \\
\text { concentration }\end{array}$ & Hexane & {$[47,49]$} \\
\hline & Self-collection & $\mathrm{Ba}\left(\mathrm{O}^{i} \mathrm{Pr}\right)_{2}, \mathrm{Sr}\left(\mathrm{O}^{i} \mathrm{Pr}\right)_{2}, \mathrm{Ti}\left(\mathrm{O}^{i} \mathrm{Pr}\right)_{4}$ & $\begin{array}{l}14^{\circ} \mathrm{C} \\
4-10 \text { hours } \\
\text { (aging) }\end{array}$ & $7-12 \mathrm{~nm}$ & $\mathrm{Ba}_{0.7} \mathrm{Sr}_{0.3} \mathrm{TiO}_{3}$ & $\begin{array}{l}\text { by water } \\
\text { content }\end{array}$ & Polar solvents & {$[51]$} \\
\hline Micro-emulsion & - & $\mathrm{Ba}(\mathrm{OH})_{2}+\mathrm{Ti}(\mathrm{OBu})_{4}$ & $\begin{array}{l}\text { Aging } 24 \mathrm{~h} \text { at } \\
\text { R.T. }\end{array}$ & $5-10 \mathrm{~nm}$ & BTO & by micelle size & & {$[55]$} \\
\hline $\begin{array}{l}\text { Super-critical } \\
\text { precipitation }\end{array}$ & - & $\operatorname{BaTi}\left(\mathrm{O}^{i} \mathrm{Pr}\right)_{6}$ & $\begin{array}{l}300^{\circ} \mathrm{C} \\
10 \mathrm{MPa}\end{array}$ & $10 \mathrm{~nm}$ & ВТО & $\begin{array}{l}\text { by reactor } \\
\text { conditions }\end{array}$ & & [57] \\
\hline Bio-inspired & Peptide template & $\mathrm{BaTi}\left(\mathrm{O}_{2} \mathrm{CC}_{7} \mathrm{H}_{15}\right)\left[\mathrm{OCH}\left(\mathrm{CH}_{3}\right)_{2}\right]_{5}$ & $\begin{array}{l}\text { R.T. } \\
1-4 \text { days }\end{array}$ & $12 \mathrm{~nm}$ & $\begin{array}{l}\text { Tetragonal } \\
\text { BTO }\end{array}$ & by adjusting $\mathrm{pH}$ & & {$[62]$} \\
\hline
\end{tabular}


route for the preparation of novel materials. ${ }^{[19]}$ Examples of zeolites, ${ }^{[20]}$ metal-organic frameworks, ${ }^{[21]}$ nanocrystalline titania, ${ }^{[22]}$ etc. are considered the current benchmarks for materials comparison. Solvothermal and hydrothermal syntheses are the most exploited routes for preparing ternary oxides, with most of the literature examples belonging to this strategy. These techniques are based on the crystallization and growth of the desired product at moderate temperatures and autogenous pressure. These conditions are achieved by heating the reaction mixture in a sealed reactor (autoclave) above the boiling point of the organic solvent (solvothermal) or above the boiling point of water (hydrothermal). They are typically one-step processes in which the products are used after purification without any further crystallization step. ${ }^{[19]}$

\subsubsection{Hydrothermal, Aqueous Solution-based Synthesis}

The first synthetic recipes date back to the 1970s for the specific case of $\mathrm{BaTiO}_{3}$ (BTO). ${ }^{[23]}$ However, it was only in 2005 that a procedure for the synthesis of nanosized $(<20 \mathrm{~nm})$ perovskite nanocrystals was reported. ${ }^{[24]}$ Although the nanocrystal size is slightly larger than the scope of this review, the work is of special importance due to its versatility. Barium nitrate and titanium chloride (III) were used as starting materials in a highly alkaline solution of $\mathrm{NaOH}(5-10 \mathrm{M})$ at temperatures in the range 140-200 ${ }^{\circ} \mathrm{C}$. The resulting spherical NCs have an average size of $17 \mathrm{~nm}$ and $20 \mathrm{~nm}$ when 180 and $200{ }^{\circ} \mathrm{C}$ are used respectively. ${ }^{[24]}$ Alternative synthetic conditions can also lead to the formation of nanocubes of BTO under milder conditions and adding oleic acid, which is retained in the resulting solution. ${ }^{[25]}$ Oleic acid is an effective surfactant that enables control over particle size, crystallographic direction and enhances dispersibility of ternary oxides.[26]

\subsubsection{Solvothermal, Non-aqueous Solution-based Synthesis}

Niederberger et al. ${ }^{[27]}$ presented the first example of sub-10 $\mathrm{nm}$ NCs using this route in 2004. The synthesis is based on a non-hydrolytic pathway from the reaction of commercially available ( $\mathrm{Ti}$ and $\mathrm{Zr}$ ) isopropoxides with custom benzyl alcohol barium and strontium alkoxides. These custom alkoxides are prepared by reacting pure metals with different alcohols (i.e. benzyl alcohol, $\mathrm{BnOH}$ ), a reaction that forms hydrogen gas as by-product (Eqn. (2)). ${ }^{[28]}$ The process is performed at a temperature range from 50 $100{ }^{\circ} \mathrm{C}$, depending on the electropositivity of the metal. In that sense, strontium would require higher reaction temperatures to achieve complete dissolution of the metal compared to the barium analogous process.[27a]

$$
\mathrm{Ba}+2 \mathrm{BnOH} \rightarrow \mathrm{Ba}(\mathrm{OBn})_{2}+\mathrm{H}_{2} \uparrow
$$

One equivalent mole of the corresponding ( $\mathrm{Ti}$ or $\mathrm{Zr}$ ) isopropoxide is then added, and the mixture is transferred to the autoclave and heated at $200-220^{\circ} \mathrm{C}$ for $48-72$ hours. The resulting products are crystalline and spherical in morphology. The measured size of the NCs is as follows: BTO (4-5 nm, Fig. 2), [27a] $\mathrm{SrTiO}_{3}(5-10 \mathrm{~nm})^{[27 \mathrm{a}]}$ and $\mathrm{BaZrO}_{3}(2-3 \mathrm{~nm}$, agglomerated).[27b]

The mechanism of this synthesis was elucidated by ${ }^{1} \mathrm{H}$, ${ }^{13} \mathrm{C}-\mathrm{NMR}$ spectroscopy and coupled gas chromatography-mass spectrometry (GC-MS). The reaction undergoes a $\mathrm{C}-\mathrm{C}$ bond formation from the benzyl alcohol and isopropanol species (Scheme 1 ), which represents a third pathway from the well-known ester and alkyl halide non-aqueous eliminations. ${ }^{[29]}$

Although this represents a pure solvothermal procedure, variations from this example have employed water as an oxygen source for other systems that cannot proceed with the $\mathrm{C}-\mathrm{C}$ mechanism described before or simply to improve crystal size tunability without compromising crystallinity. ${ }^{[30]}$ Here we find custom barium ethoxides or isopropoxides; commercially available single barium

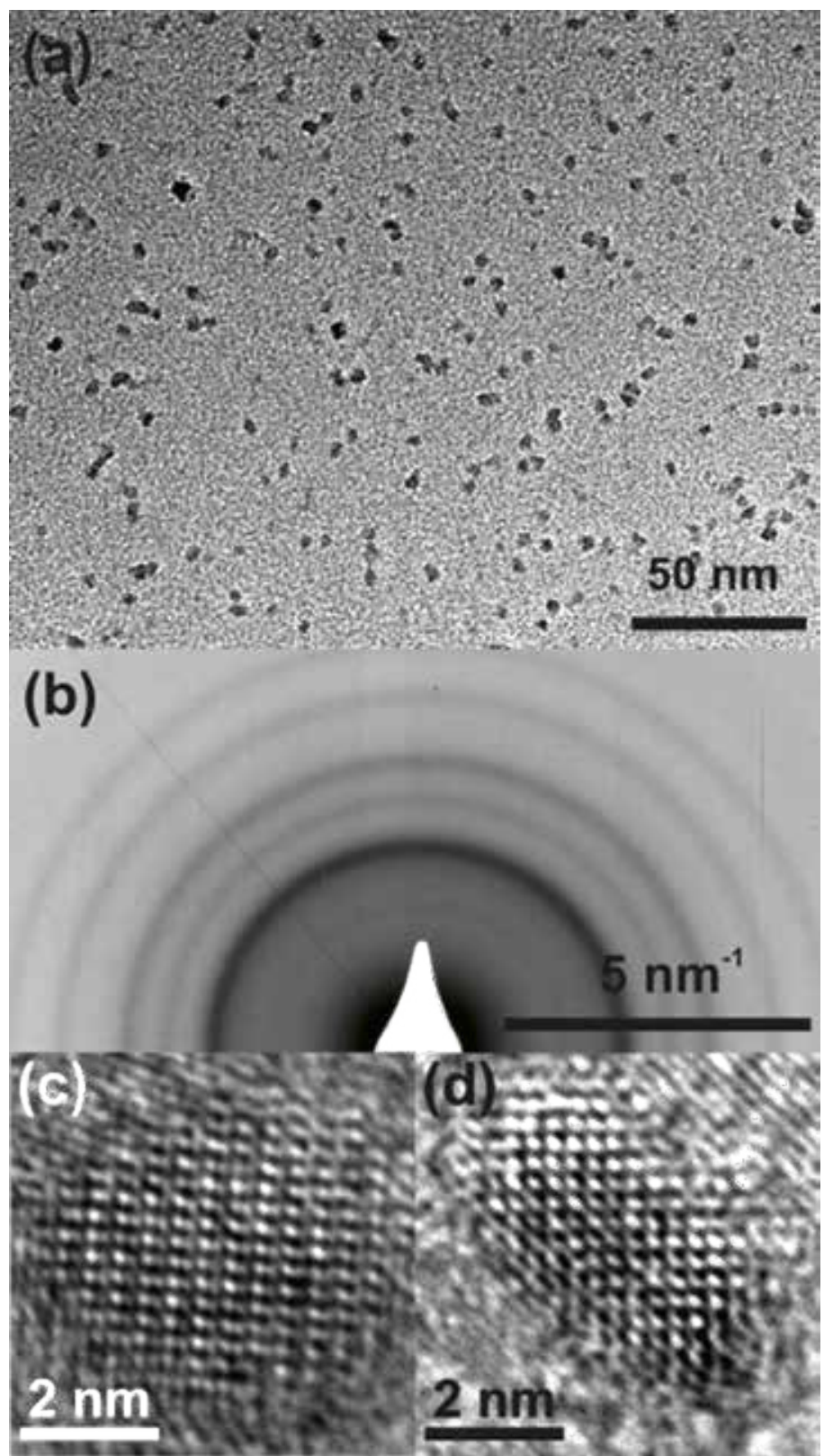

Fig. 2. Representative TEM micrographs of as-synthesized BaTiO nanoparticles. (a) An overview image proves the exclusive presence of $\mathrm{BaTiO}_{3}$ nanoparticles without the presence of larger particles or agglomerates; (b) selected area electron diffraction (SAED); (c) and (d) highresolution TEM images of isolated $\mathrm{BaTiO}_{3}$ nanocrystals. Reprinted with permission from ref. [27a]. Copyright 2004 American Chemical Society.

and titanium isopropoxides (Alfa Aesar) or even double barium titanium ethylhexano-isopropoxide (Alfa Aesar) that also lead to the formation of BTO NCs. ${ }^{[30 \mathrm{~b}]}$ All preparations were performed at $200{ }^{\circ} \mathrm{C}$ for $48-96$ hours depending on the metal source and solvent compositions.

There is another set of reactions that use as $\mathrm{A}^{2+}$ sources different aqueous solutions of hydroxides, ${ }^{[31]}$ chlorides $^{[32]}$ or nitrates. ${ }^{[33]}$ However, these reactions typically go through a hydrolysis and condensation mechanism. They take advantage of the highly charged Lewis acidic $\mathrm{B}^{4+}$ metal centers in alkoxides (isopropoxides or butoxides) to force the reactivity into the formation of the ternary oxide. In the case where hydroxides are used, no additional base is required as the reagents serve as the hydroxyl source, and therefore the initiator of the reaction. Among them, special interest arose in the synthesis presented by the Caruntu group. Their adapted method, which is thought to go under the formation of a microemulsion system at solvothermal conditions, is able to 


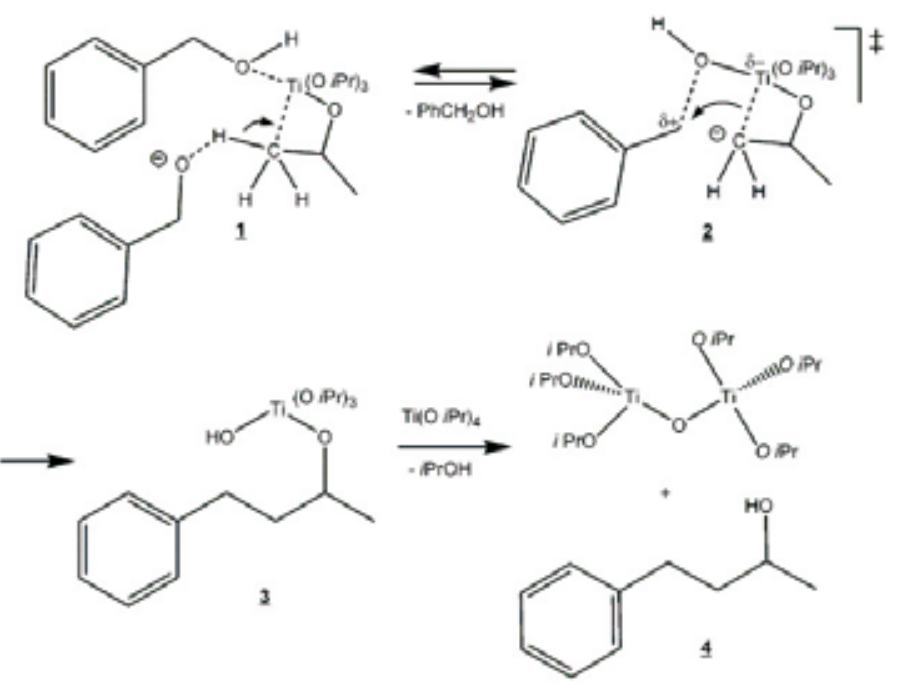

Scheme 1. Reaction mechanism for the formation of $\mathrm{BaTiO}_{3}$ nanoparticles and illustrating the $\mathrm{C}-\mathrm{C}$ bond formation leading to 4-phenyl-2-butanol. Reprinted with permission from ref. [27a]. Copyright 2004 American Chemical Society.

produce $10 \mathrm{~nm}$ BTO nanocubes that can be stabilized in polar and non-polar media, following (if required) a ligand exchange process. ${ }^{[33]}$ Smaller BTO nanocrystals can also be obtained in a rapid (6 hours) solvothermal method described by Yoshimura and coworkers. The reacting solvents are slowly released, in a process named 'Solvothermal drying route', that can lead to the formation of BTO nanopowders with tunable size (smallest $c a .5 \mathrm{~nm}$ ) and crystal structure (cubic and tetragonal). ${ }^{[31 \mathrm{~b}]}$

\subsubsection{Oil-(or Surfactant) Water Two-phase Solvothermal Synthesis}

This intermediate strategy is based on the crystallization and growth of nanocrystals at the oil-water interface but the reaction is conducted under solvothermal conditions. Briefly, this approach allows the use of strong alkali environments (necessary in hydrothermal synthesis) together with the benefit of incorporating surfactants that passivate NCs surfaces, therefore avoiding secondary growth or agglomeration. Alkali oleates from hydroxides or acetates are initially produced. Acetates are typically preferred due to the lower sensitivity to $\mathrm{CO}_{2}$ and therefore avoiding the formation of barium carbonate impurities. ${ }^{[34]}$ As in the solvothermal routes, the $\mathrm{B}^{4+}$ is provided in the form of alkoxides. The thermal process is conducted in the range of $180-200^{\circ} \mathrm{C}$ for a time range between 12-78 hours. $3.7 \mathrm{~nm}$ BTO nanocuboids, ${ }^{[34]} 10 \mathrm{~nm} \mathrm{SrTi}{ }_{1-x} \mathrm{Zr}_{\mathrm{x}} \mathrm{O}_{3}$ nanocuboids ${ }^{[35]}$ monodisperse nanocrystal are obtained, with the possibility of transition-metal doping ( $\mathrm{Cr}, \mathrm{Mn}, \mathrm{Fe}$ or $\mathrm{Co}){ }^{[36]}$

\subsection{Sol-gel Precipitation}

Controlled hydrolysis and polycondensation of a metal alkoxide precursors (butoxides) and a metal salt (hydroxides) are the basis for this method. The reaction takes place in alcohol-based media (i.e. ethylene glycol (EG) and higher glycols as di-(DEG), tri-(TEG) and tetra-ethylene glycol) with the presence of polyvinyl pyrrolidone (PVP) as surfactant. The mixture is heated at $160{ }^{\circ} \mathrm{C}$ for $0.25-2$ hours. The NCs formed are dispersed into the sol as observed via DLS. Precipitation can be then triggered by adding water to the solvent mixture, which removes solvent molecules attached to the surface of the NCs and destabilizing the sol. The material obtained is then washed with water and ethanol. Remarkably, this process features the formation of extremely small BTO NCs, which are in the range of $2.8 \mathrm{~nm}$ using DEG or $5.1 \mathrm{~nm}$ using TEG.[37] The authors used the TEG system to investigate the effect of the experimental conditions through a range of reagent concentrations. They found that in the experimental conditions where sols are formed, the system is robust in regards to the final particle size. However, at higher concentrations (high-alkaline media) the sols are no longer stable and result in the formation of precipitates. This results in the formation of larger aggregates and therefore an increase in the XRD measured crystallite size. ${ }^{[38]}$ STO NCs with an average size of $8.6 \mathrm{~nm}$ (TEM and DLS presented in Fig. 3) could also be obtained following this route, with the necessary addition of ammonium hydroxide. [39]
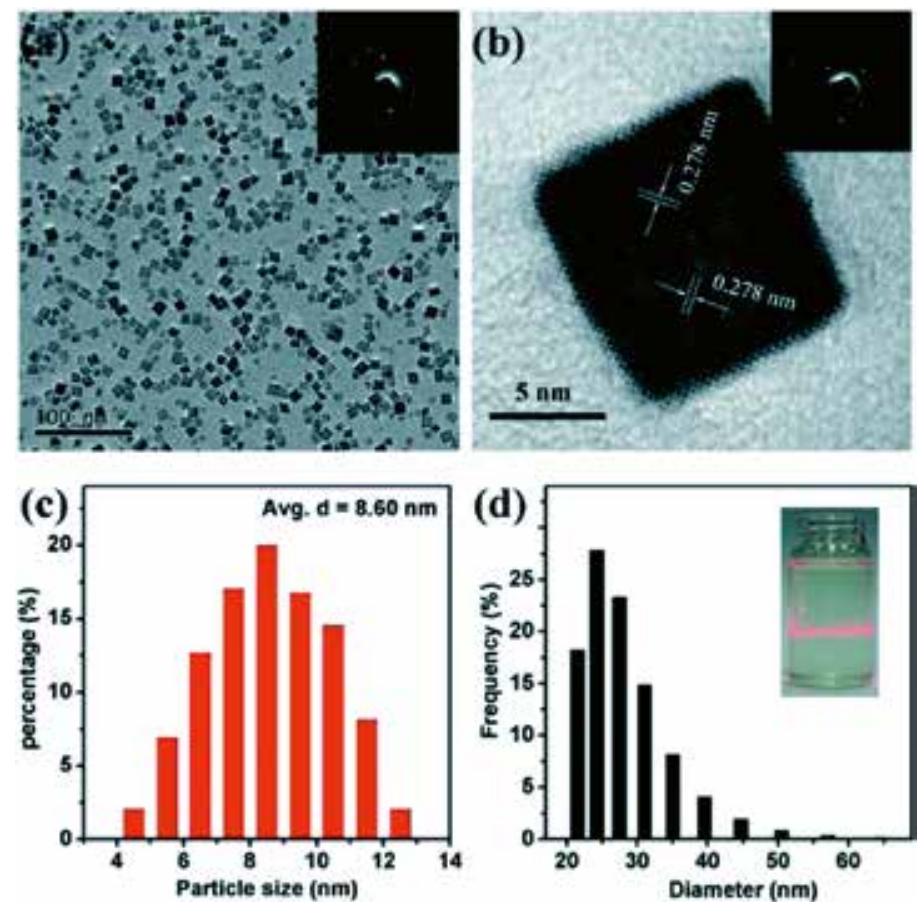

Fig. 3. (a) TEM image, (b) HR-TEM image, (c) particle size distribution of the $\mathrm{SrTiO}_{3}$ nanocubes, and (d) DLS analysis of the $\mathrm{SrTiO}_{3}$ nanocrystal sol prepared by the rapid sol-precipitation method at $160^{\circ} \mathrm{C}$ for $2 \mathrm{~h}$. Reproduced from ref. [39] with permission from The Royal Society of Chemistry.

\subsection{Vapor-diffusion Sol-gel}

Vapor-diffusion sol-gel (VDSG) methods are based on the hydrolysis and polycondensation of double metal alkoxide precursors (commercially available, e.g. Gelest Inc.) by pumping water vapor (hydrolytic agent) into the reaction flask (Fig. 4). The Brutchey group was able to produce different oxides with the general formula of $\mathrm{Ba}_{1-\mathrm{x}} \mathrm{Sr}_{\mathrm{x}} \mathrm{Ti}_{1-\mathrm{y}} \mathrm{Zr}_{\mathrm{y}} \mathrm{O}_{3}$. Ternary oxides such as $\mathrm{BTO},{ }^{[40]} \mathrm{STO}{ }^{[41]}$ and $\mathrm{BZO}{ }^{142]}$ are prepared by a one-step procedure in which the reagents are exposed to a humid vapor flow for $72 \mathrm{~h}$. During this time, an increased viscosity is firstly observed followed by the formation of a fully rigid, monolithic and crack-free gel (after 4-8 hours depending on the flow rate). A few hours after, cracks start to appear along with a clear supernatant. The water flow is stopped after 72 hours and the pieces of the gel are collected, washed with ethanol, sonicated and recovered via centrifugation. An off-white powder consisting of BTO NCs was finally obtained $\left(5.9 \pm 0.1 \mathrm{~nm}\right.$ in size, TEM) ${ }^{[40]}$ which can be dispersed directly in ethanol[43] or in toluene after surface modification with $n$-hexylphosphonic acid. ${ }^{[4]}$ This methodology also allows the preparation of doped NCs by addition of metal salts in the reaction mixture, e.g. $\mathrm{Ba}_{1-\mathrm{x}} \mathrm{La}_{\mathrm{x}} \mathrm{TiO}_{3}{ }^{[45]}$ or Eu:BaZrO${ }_{3} \cdot{ }^{[46]}$

\subsection{Hot-injection Sol-gel}

Most of the examples belonging to this category depend on the hot injection of a metallic precursor in a suitable solvent in the 


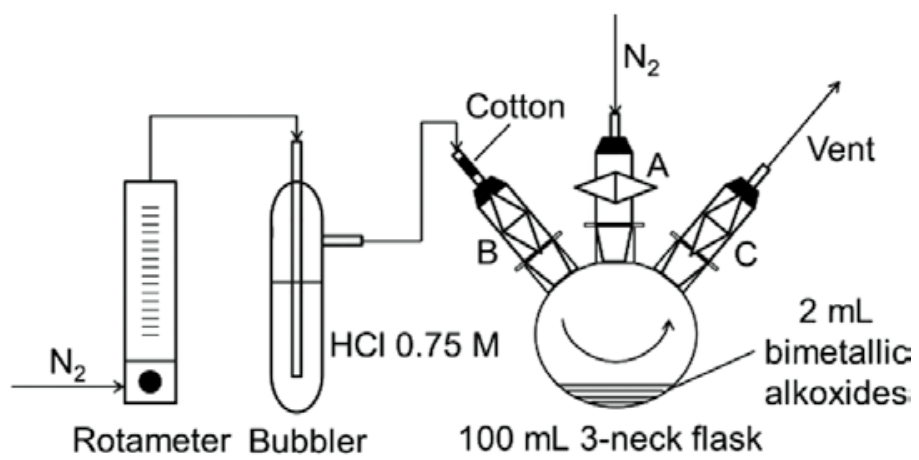

Fig. 4. Employed set-up for the VDSG synthesis. Two configurations are possible: (1) precursor injection (A open, $C$ closed, and a septum replaces B), and (2) vapor diffusion (A closed, and B and C open). Reproduced from ref. [43] with permission from The Royal Society of Chemistry.

presence of a ligand that impacts colloidal stability. In a typical BTO run, barium titanium ethyl hexane-isopropoxide precursor is injected in a mixture of diphenyl ether and oleic acid at $140{ }^{\circ} \mathrm{C}$ under an inert atmosphere. Argon or nitrogen are required to avoid the premature hydrolysis of precursors due to their high sensitivity to moisture. Hydrogen peroxide is subsequently injected once the mixture is at $100{ }^{\circ} \mathrm{C}$ to promote further hydrolysis and crystallization of the product. After $48 \mathrm{~h}$ the product obtained consists of spherical monodisperse BTO NCs with an average diameter of $8 \mathrm{~nm}$. The authors could establish a relation between the reagent concentration (precursor to oleic acid ratio) and final size of particles. By increasing this parameter (and adding extra $\mathrm{H}_{2} \mathrm{O}_{2}$ ) bigger particles in the range of 9-12 nm were obtained with a cubic morphology, whereas decreasing this parameter would lead to 4-6 nm NCs. ${ }^{[47]}$ Using a similar procedure, but in this case with metallic glycolate precursors (preparation described in ref. [48]), spherical STO and BTO nanoparticles were successfully produced in the range of $3-5 \mathrm{~nm}^{[49]}$ with a similar reagent concentrationsize dependence as observed before. ${ }^{[4]}$ Alternatively, a custom barium-benzyl alcohol (described elsewhere) ${ }^{[27]}$ together with Ti-isopropoxide as metal precursors were used to obtain $3-5 \mathrm{~nm}$
BTO NCs in a oleylamine/oleic acid reaction mixture at $320{ }^{\circ} \mathrm{C}$ for $48 \mathrm{~h}$. In this case, the size effect was studied depending on the caping agent (decanoic acid or oleic acid) and the effect of the addition of oleyl alcohol during precursor synthesis. The presence of this alcohol improves morphology and leads to smaller particles due to the improved coordination capabilities compared to benzyl alcohol. ${ }^{[50]}$

\subsection{Self-collection Growth}

The self-collection growth technique refers to the controlled hydrolysis of metallic precursors that leads to the formation of a pure high crystalline gel monolith. It was presented by the O'Brien group in 2015 for $\mathrm{BaTiO}_{3}, \mathrm{Ba}_{\mathrm{x}} \mathrm{Sr}_{1-\mathrm{x}} \mathrm{TiO}_{3}$ and the quaternary oxide $\mathrm{Ba}_{0.65} \mathrm{Sr}_{0.35} \mathrm{Ti}_{0.5} \mathrm{Hf}_{0.5} \mathrm{O}_{3}$. ${ }^{[51]}$ The reaction is initiated by mixing metallic isopropoxides in ethanol/water mixtures and applying mild heat $\left(55^{\circ} \mathrm{C}\right)$. The formation of the gel is started after 2 hours, with gelation completed after 5 hours (Fig. 5A). The main feature of this approach is the absence of post-processing, as no by-products are observed. The collected monolith is only rinsed with ethanol and the NCs are directly dispersed into the selected solvent. Contrary to most of examples reviewed before, the nanoparticles obtained via this method can be dispersed in polar solvents (e.g. ethanol or furfural alcohol) leading to transparent solutions with a total concentration of $10-50 \mathrm{mg} \cdot \mathrm{mL}^{-1}$. The NCs have a tunable size in the range of 7-12 nm, mainly affected by the water content and not by the experiment temperature (Fig. 5C). ${ }^{[51]}$ Following the same procedure, iron substituted $\mathrm{Ba}\left(\mathrm{Ti}_{1-\mathrm{x}} \mathrm{Fe}_{\mathrm{x}}\right) \mathrm{O}_{3}$ and pure $\mathrm{BaFeO}_{3}$ may be also produced. ${ }^{[52]}$

\subsection{Microemulsion}

The use of microemulsion for the preparation of oxides or mixed oxide particles is known since the late 1980s. In this wet-chemistry method, the control is based on the nanoreactors formed by the inverse micelles. This system was presented in 1995 for a wide variety of compositions, including double titania $\left(\mathrm{TiO}_{2}\right)$ and zirconia $\left(\mathrm{ZrO}_{2}\right)$ and ternary $\mathrm{BaZrO}_{3}, \mathrm{BaTiO}_{3}, \mathrm{SrTiO}_{3}$ and $\mathrm{SrZrO}_{3} \cdot{ }^{[53]}$ Metal alkoxides were mixed with the microemulsion formed by cyclohexane and polyoxyethylene-(4)-laurylether. BTO and STO were analyzed after synthesis, whereas BZO and
A

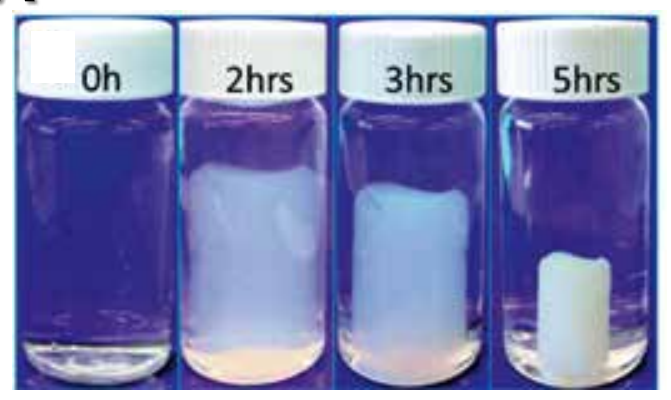

C

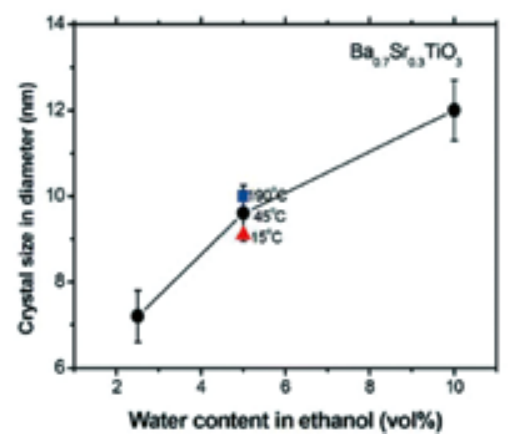

B
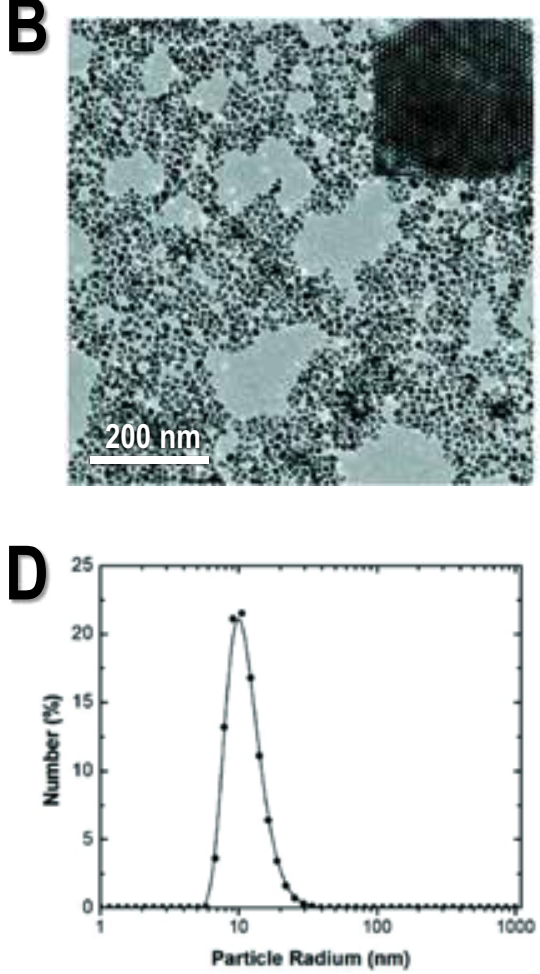

Fig. 5. (A) Photo images. (B) TEM image of BST nanocrystals (inset: high-resolution image of a particle oriented along the [111] direction). (C) Diameter of BST nanocrystals as a function of water content in ethanol solvent. The crystal size range is the error bar nanocrystals synthesized at the temperature of $15-190^{\circ} \mathrm{C}$ (red triangle: $15^{\circ} \mathrm{C}$, black circle: $45^{\circ} \mathrm{C}$, and blue cube: $190^{\circ} \mathrm{C}$ ). (D) Size distribution of BST nanocrystals by number (measured by dynamic light scattering). Adapted from ref. [51] with permission from The Royal Society of Chemistry. 
SZO required a sintering process at $800{ }^{\circ} \mathrm{C}$ and $900{ }^{\circ} \mathrm{C}$, respectively. All phases contained crystallites below $20 \mathrm{~nm}$, mostly in the form of aggregated nanopowders. In more recent examples, the direct synthesis (without crystallization step) of ternary oxides via emulsion systems was realized. Yang and coworkers, ${ }^{\text {[54] }}$ published in 2007 the preparation of $\mathrm{BaTiO}_{3}, \mathrm{SrTiO}_{3}$ and mixed $\mathrm{Ba}_{\mathrm{x}} \mathrm{Sr}_{1-\mathrm{x}} \mathrm{TiO}_{3} \mathrm{NCs}$ in a cyclohexene, Triton X-100 (surfactant), n-butanol water mixtures $\left(80^{\circ} \mathrm{C}\right)$ while Zhou and coworkers, ${ }^{[55]}$ used an hexanol-water based microemulsion $\left(70^{\circ} \mathrm{C}\right)$ with $\mathrm{OP}-10$ and cyclohexane as surfactant and assisted surfactant for their BTO route. Both systems present similarities in the experimental observations of size dependence. The size of the micelles can be adjusted by varying the water-surfactant ratio, and therefore different sets of sizes can be obtained, with the smallest set in the range of 5-10 $\mathrm{nm}$.

\subsection{Supercritical Fluid Technology}

Supercritical fluids represent a consolidated green platform for the synthesis and processing of materials, including the direct crystallization of nanomaterials under supercritical conditions. ${ }^{[56]}$ This process may be considered a solvothermal process that takes place at supercritical conditions. The main advantage is easy implementation in a continuous production due to the readily available technology. Based on the hydrolysis and polycondensation of the $\mathrm{BaTi}\left(\mathrm{O}^{i} \mathrm{Pr}\right)_{6}$ in a water/ethanol mixture at supercritical conditions, BTO nanoparticles of average size 10 nm were recovered. ${ }^{[57]}$ This process was then used for the synthesis of different $\mathrm{BaTi}_{1-\mathrm{y}} \mathrm{Zr}_{\mathrm{y}} \mathrm{O}_{3}(0 \leq \mathrm{y} \leq 1)$ nanocrystals. Philippot et al. ${ }^{[58]}$ studied the whole range of compositions at higher temperatures obtaining the entire solid solution, confirmed with the linear variation of the lattice parameter (Vegard's law). Pure BTO was the largest composition obtained $(20 \pm 6 \mathrm{~nm})$. The size decreased by increasing the zirconium content, until pure BZO with an average size of $10 \pm 2 \mathrm{~nm}$ was obtained (Fig. 6A). A more in-depth study was presented one year after[59] by applying in situ synchrotron wide-angle XRD scattering (WAXS). The authors were able to study the effect of the $\mathrm{Zr}$ content and found to have a direct impact over the growth of nanocrystals. The crystallite size was the studied parameter across the different zirconium compositions of the $\mathrm{BaTi}_{1-y} \mathrm{Zr}_{\mathrm{y}} \mathrm{O}_{3}$ (BTZ) ceramic. Increasing the zirconium content resulted in a decrease of the crystallite size (Fig. 6A), together with a significant decrease in the amount of relative crystal growth. For example, the case of $y=0.3$ the crystallite size at 8 minutes is almost the same as after only 10 seconds (Fig. 6B). This phenomenon is similar to the one observed in this same work by screening the precursor concentration and may be explained on the basis of the nucleation and growth theory developed by LaMer and Dinegar. ${ }^{[60]}$ During nucleation the amount of available precursor decreases. At low precursor concentrations, the minimum concentration condition for nucleation is quickly not present and therefore growth will start to occur, consuming the rest of precursor present and increasing crystallite size via various growth mechanism. For high precursor concentrations, nucleation will play a more significant role, occurring at a faster time scale in a 'burst-nucleation'-like behavior. The fast depletion of precursor concentration results in very limited growth and therefore crystallites being formed by precursor condensation and not by ripening. This explanation was used by the authors to rationalize the effect of the $\mathrm{Zr}$ concentration. The minimum concentration for burst-nucleation decreases with increased $\mathrm{Zr}$ content, being nucleation the simply dominant at high $\mathrm{Zr}$ concentrations.

\subsection{Biological and Biomimetic Systems}

Production methods that take place at room temperature are probably the ultimate goal of any synthetic chemist. Biological and biomimetic methods provide economically viable, environmentally benign and energy-conserving processes. ${ }^{[61]}$ As in nature, these systems can produce crystals controlled by the properties of the biological templates. This is especially important in $\mathrm{BaTiO}_{3}$, where the tetragonal phase is of interest whereas the cubic phase is generally obtained for being the most thermodynamically stable. To force a cubic to tetragonal phase conversion, extra high-temperature steps are required, which may result in particle aggregation or coarsening. Nuraje et al. ${ }^{[62]}$ provided the first example of a ternary oxide (BTO) using a peptide nanoring as template. The controlled hydrolysis of a Ba-Ti alkoxide occurs inside the nanoreactor formed by the self-assembled peptide. After time periods ranging from 1-4 days, ring-shaped self-assemblies appear. The templates are removed by irradiating the solution with UV light $(\lambda=355 \mathrm{~nm})$ for $10 \mathrm{~h}$. The nanocrystals obtained are monodisperse in the range of 6-12 $\mathrm{nm}$. The sizes can be tuned by modifying the solution's $\mathrm{pH}$ since this parameter has a direct influence over the template diameter. Surprisingly, the NCs present a tetragonal structure, possibly induced by the surface structure of the peptide template and the high surface tension inside the cavity. The resulting NCs show ferroelectric behavior. Biological methods are then able to crystallize metastable crystal structures. Another alternative approach relies on the use of microorganisms for the formation of BTO. Conventionally synthetized BTO powder was digested by yeast cells resulting in spherical BTO nanoparticles in the range of 8-21 nm. ${ }^{[63]}$ Improved results were obtained when barium and titanium compounds were used together with fungus F. oxysporum. ${ }^{[61]}$ This technique was also used by the same group for other binary phases such as silica, ${ }^{[64]}$ titania, ${ }^{[64 a]}$ zirconia, ${ }^{[65]}$ or magnetite. ${ }^{[66]}$ The reaction undergone under ambient conditions for $24 \mathrm{~h}$ resulted in the formation of nanocrystalline BTO of 4-5 $\mathrm{nm}$ in average size. The authors claimed that the nanoparticles can

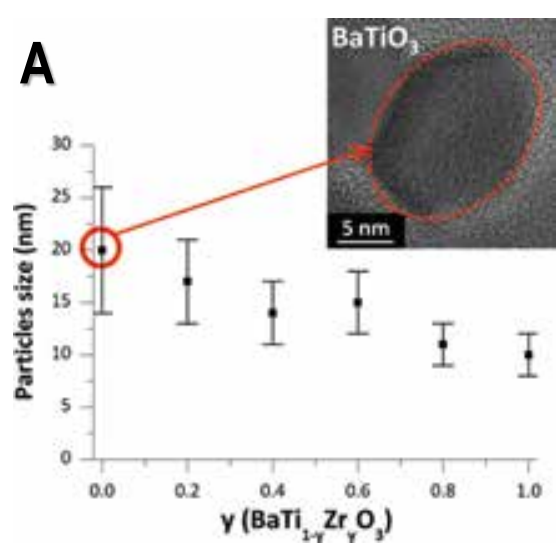

B

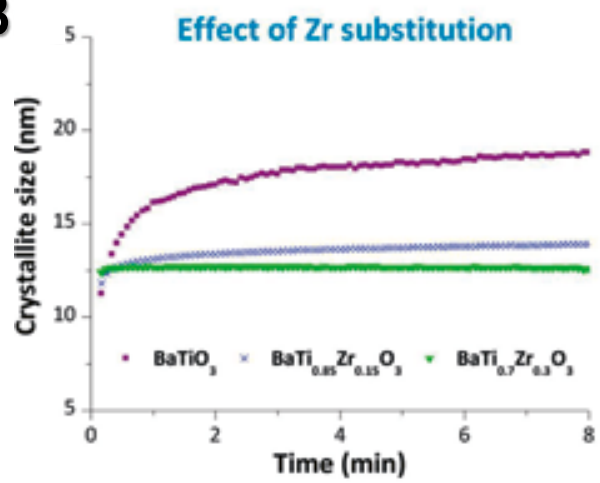

Fig. 6. (A) Variation of the BTZ mean nanocrystals size, together with size distributions from HR-TEM images (> 150 NCs). (B) in situ synchrotron WAXS study of the BTZ system with variation of the crystallite size as a function of time for $\mathrm{BaTiO}_{3}$, $\mathrm{BaTi}_{0.85} \mathrm{Zr}_{0.15} \mathrm{O}_{3}$, and $\mathrm{BaTi}_{0.7} \mathrm{Zr}_{0.3} \mathrm{O}_{3}$. Adapted with permission from ref. [59]. Copyright 2016 American Chemical Society. 
be dispersed in PMMA/chlorobenzene or water, but no solution characterization is provided.

\section{From Stable Colloids to Applications}

Above, we presented the main strategies developed for the preparation of oxide perovskite NCs. There are still some challenges that need to be overcome to arrive at a general strategy. While the research in this area continues, an important number of applications are starting to emerge. In this second part, the main benefits of stable colloids will be highlighted in low-temperature solution-based processes. Therefore, the direct utilization of nanocrystalline powders will not be discussed.

\subsection{Ferroelectric Thin Films}

Ferroelectric materials exhibit spontaneous electric polarization that can be reversed by applying an external electrical field. The switchable polarization has been exploited in several applications, such as memory devices in the form of ferroelectric capacitators or integrated microelectronics. ${ }^{[67]}$ Lead zirconate (PZT) is the most well-known representative of this class. Nevertheless, researchers have sought to develop lead-free alternatives, especially $\mathrm{BaTiO}_{3}$ (BTO) and derived compositions. [68] The use of BTO nanocrystals as nanoscale building blocks allows for (i) a more detailed control over the grain size of the final film, (ii) an increasing polarization or dielectric constant, or (iii) a better control over a range of electrical characteristics by selective annealing to different grain sizes. ${ }^{[69]} \mathrm{A}$ more fundamental research interest arises also from the study of the size-effect on the ferroelectric properties. ${ }^{[70]}$ A typical fabrication process will include two steps: a first deposition of the material on the desired surface (i.e. $\mathrm{Si}, \mathrm{Ni}, \mathrm{Pt}-\mathrm{TiO}_{2}$, etc.) and a second annealing step for film densification. The straightforward strategy is the dispersion of BTO NCs in a proper solvent like 2-methoxyethanal or 2-methoxyethanol and deposition via spin-coating or electrophoretic deposition. ${ }^{[71]}$ On the other hand, alternative methods rely on stabilized BTO NCs as initial building blocks. Alcohol ${ }^{[69]}$ and water-based ${ }^{[72]}$ solutions also lead to the formation of BTO films. Robinson and coworkers, ${ }^{[69]}$ reported that NCs dispersions can be used in different methodologies, from deposition of individual NCs on a substrate to soft-lithography in forms of micromolding in capillaries (MIMIC). Nevertheless, each strategy requires a different approach regarding the colloidal engineering. This becomes crucial when BTO NCs are individually deposited on different substrates. For instance, BTO $\mathrm{NCs}$ deposited on $\mathrm{Si}$ and $\mathrm{Si}_{3} \mathrm{~N}_{4} / \mathrm{Si}$ show different size distributions due to the interaction with the surface of the substrate. And this situations worsens when the solutions are deposited on Pt-coated silicon substrates, where the NCs tend to aggregate (AFM tapping mode image, Fig. 7A). The addition of triblock copolymer P123 improved the dispensability of the NCs (Fig. 7B) due to a possible different surface binding and compatibility enhanced by the incorporation of additional surfactants.

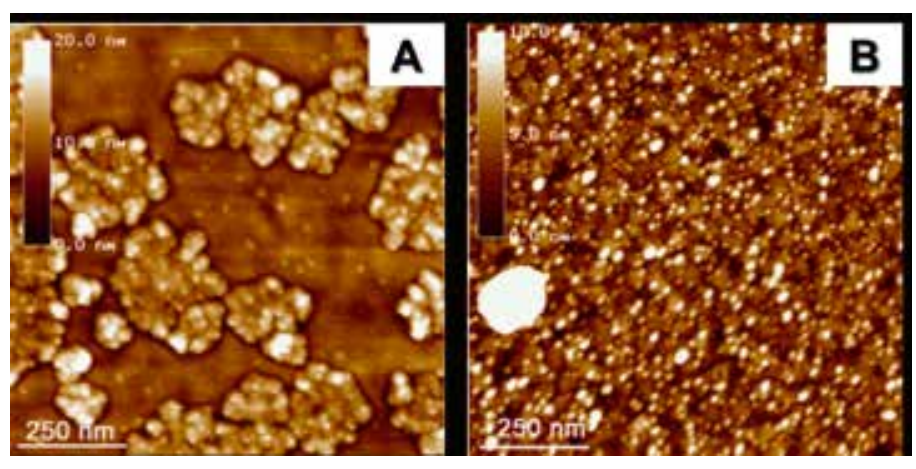

Fig. 7. Tapping mode AFM images of BTO NCs on Pt-coated $\mathrm{SiO}_{2} /$ Si substrates, with $(A)$ showing a large degree of aggregation and $(B)$ presenting well dispersed NCs by addition of P123 surfactant. Adapted from ref. [69], with the permission from AIP publications.

\subsection{Nanocomposites for Flexible Ferroelectric Capacitors}

The combination of nanocrystals and organic polymeric structures has gained interest in recent years due to the synergetic relationship between the individual components, resulting in superior performances. All-solid dielectric capacitors are ideal candidates for some niche applications as in portable electronic devices, electrical power systems, and hybrid electric vehicles in the form of multi-layer ceramic capacitators (MLCCs). Although $\mathrm{BaTiO}_{3}$ has been traditionally the dominant material, its poor mechanical properties have limited its applicability in flexible capacitors. On the other hand, polymers are widely investigated in flexible electronics due to their excellent mechanical properties and easy solution processability. However, their dielectric constant values are several orders of magnitude lower compared to conventional ceramics and low energy densities are thus obtained (in linear dielectric behaviour, energy density is directly proportional to the dielectric constant). ${ }^{[73]}$ To overcome this, incorporation of BTO NCs in the form of 0-3 composites (connectivity classification for piezoelectric composites, 0 for the active phase (NCs) and 3 for the passive phase (3D polymer)) has been proposed as an efficient solution to obtain high dielectric constants from the ceramic filler with high DC-breakdown strength from the polymer matrix. The process is illustrated in Fig. 8. The BTO NCs are used as building blocks. They are stabilized by oleic acid ligands, and dispersed in toluene. ${ }^{[74]}$ If DMF would be preferred, the original ligands should be exchanged for inorganic ligand $\mathrm{BF}_{4}^{-[75]}$ (methodology adapted from ref. [76]) or other ligands like TEG should be used. ${ }^{[77]}$ Then the desired polymer is added (typically PVDF-HFP, PMMA-ABS or SBS) followed by sonication/stirring. The precursor is then cast or spin-coated in the desired substrate. Toluene-based precursor solutions have the advantage that they can be processed at ambient, mild conditions whereas DMF requires a thermal process above the boil-
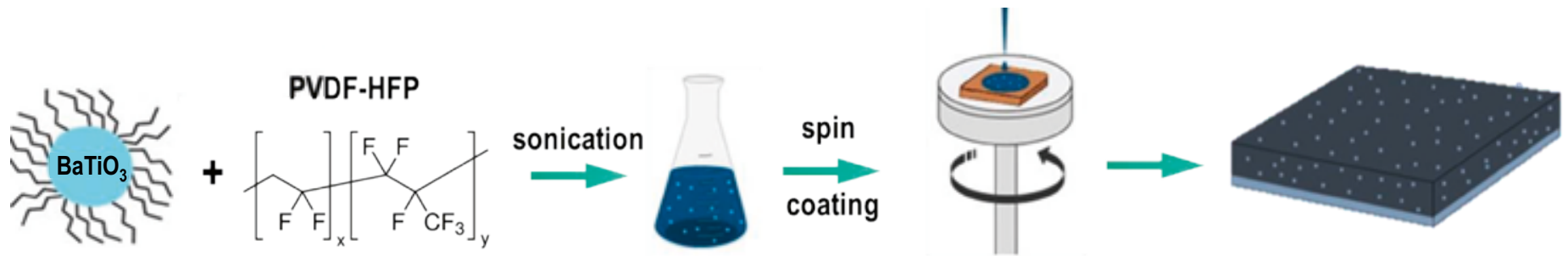

Fig. 8. Schematic illustration for the formation of BTO/PVDF-HFP nanocomposite film. 
ing point of this solvent. The resulting films contain BTO NCs homogeneously distributed in the polymer matrix, allowing a high dielectric homogeneity throughout the layer. The dielectric properties are improved thanks to the incorporation of the NCs compared to pristine polymeric layer, with high permittivity and increased energy densities as the most remarkable features.

\subsection{Superconducting Nanocomposites, Performance with Zero Energy Loss}

Superconducting materials, exhibiting zero current loss, are essential materials especially in the field of magnets, where extremely high magnetic fields cannot be achieved with traditional electromagnets. $\mathrm{REBa}_{2} \mathrm{Cu}_{3} \mathrm{O}_{7}(\mathrm{REBCO}, \mathrm{RE}=$ rare earth or $\mathrm{Y})$ coated conductors $(\mathrm{CC})$ represent the second generation of superconducting materials, and combine high performance with competitive production cost. Nanocomposite architectures (with NCs incorporated in the superconductor), are required to maintain performance at high magnetic fields. ${ }^{[78]}$ Economically feasible Chemical Solution Deposition (CSD) combined with preformed ternary oxide nanocrystals is the most promising approach ${ }^{[79]}$ for the expansion of coated conductors in the power market. The main challenge is the introduction of the stabilized nanoparticles (alcohol-based solutions) in the highly ionic TFA-REBCO (pH $=2$ ) or low-fluorine $(\mathrm{pH}=6)$ precursor solutions. ${ }^{[80]}$ The choice of the ligand has been proven to be crucial for the properties of the final superconducting nanocomposite. ${ }^{[81]}$ The Obradors ${ }^{[78,82]}$ and the Van Driessche ${ }^{[83]}$ groups have successfully incorporated a variety of sub-10 nm ternary oxides (i.e. $\mathrm{BaZrO}_{3} \mathrm{BaHfO}_{3} \mathrm{BaTiO}_{3}$ $\mathrm{SrZrO}_{3}$ ) by using triethylene glycol (TEG) and 2-(2-methoxyethoxy)acetic acid (MEEAA) as surfactants, which resulted in several weak, stable solutions that deliver epitaxial nanocomposite superconducting films. According to the work of Díez-Sierra et $a l .{ }^{[83]} \mathrm{BZO}, \mathrm{BHO}$ and SZO NCs can be homogeneously distributed in the superconducting nanocomposite, with coarsening of nanoparticles not affecting the growth of the YBCO layer. In Fig. 9 a graphical illustration of the superconducting composites is shown. The nanocrystals are depicted together with secondary phases and intergrowth. The best performance was obtained for the BHO-YBCO composites. The small size $(c a .7 \mathrm{~nm})$ of the BHO NCs in the film, maintained through the YBCO thermal process at high temperature, translates into a high concentration of pinning centers, resulting in enhanced superconducting behavior under magnetic environments.

\subsection{Memristors, beyond Moore's Law}

Resistive switches exhibit faster switching speeds, lower power consumption, higher scalability, and greater 3D stackability than standard complementary metal oxide semiconduc- tor (CMOS) circuits, thus promoting further miniaturization of electronic components. ${ }^{[84]}$ Resistive switching can be defined as the reversible change in resistance between a high resistance state (HRS) and a low resistance state (LRS) that depends on the historic applied external bias. ${ }^{[85]}$ In contrast to expensive ultrahigh vacuum nanodot fabrication approaches, solution-processed nanocrystal (NCs) research gained interest due to the physical flexibility and low fabrication cost. The Nonemann group used the flow-coating technique to deposit NCs dispersions in toluene in the form of nanoribbons. $\mathrm{SrTiO}_{3}{ }^{[86]}$ and $\mathrm{BaZrO}_{3} / \mathrm{SrZrO}_{3}{ }^{[87]}$ have successfully shown memristive behavior (Fig. 10). Special care of the selected ligands is required since they affect the performance of the assemblies. ${ }^{[88]}$

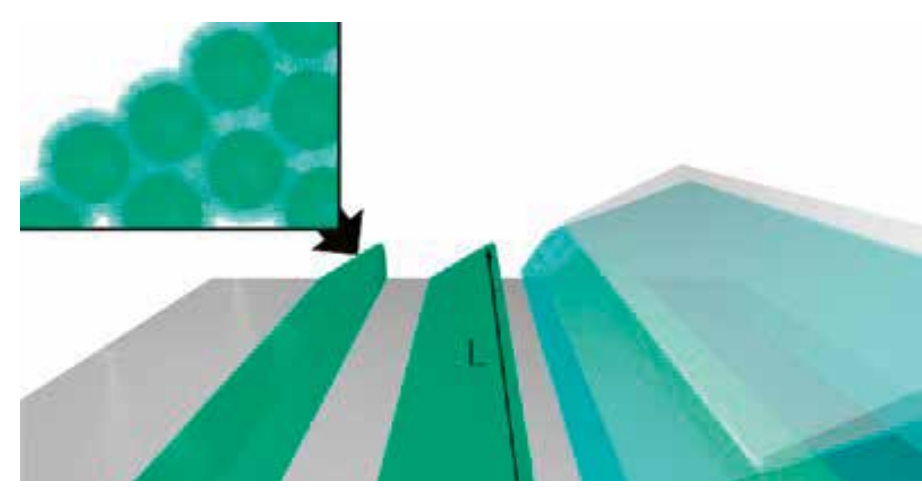

Fig. 10. Illustration of the stop-and-go flow coating process. Inset shows the assembly of the NCs driven by solvent evaporation. Adapted with permission from ref. [88b]. Copyright 2018 American Chemical Society.

\subsection{Aerogels as a Photocatalysis Platform}

Aerogels are highly porous, low-density inorganic materials traditionally based on oxides such as silica, alumina, zirconia, stannic, or tungsten oxide or a mixture of these oxides. ${ }^{[89]}$ More recently, organic aerogels have emerged with graphene oxide ${ }^{[90]}$ as the most prominent representative. Their outstanding properties are leveraged in several applications which include catalysis ${ }^{[91]}$ and adsorbents ${ }^{[90 a, 92]}$ to name a few. Their porous structure together with the possibility of tailoring their chemical properties, ${ }^{[93]}$ materializes into a powerful platform that bridges nano with macroscale. The traditional route (supercritical drying) developed by Kistler et al. ${ }^{[94]}$ in 1931 is the most used strategy for aerogel preparation. The procedure starts with gel formation, based on the polymerization and formation of $\mathrm{M}-\mathrm{OH}-\mathrm{M}$ or $\mathrm{M}-\mathrm{O}-\mathrm{M}$ bridges between the metallic atoms $(\mathrm{M})$ of the precursor molecules. ${ }^{[95]}$ This results in
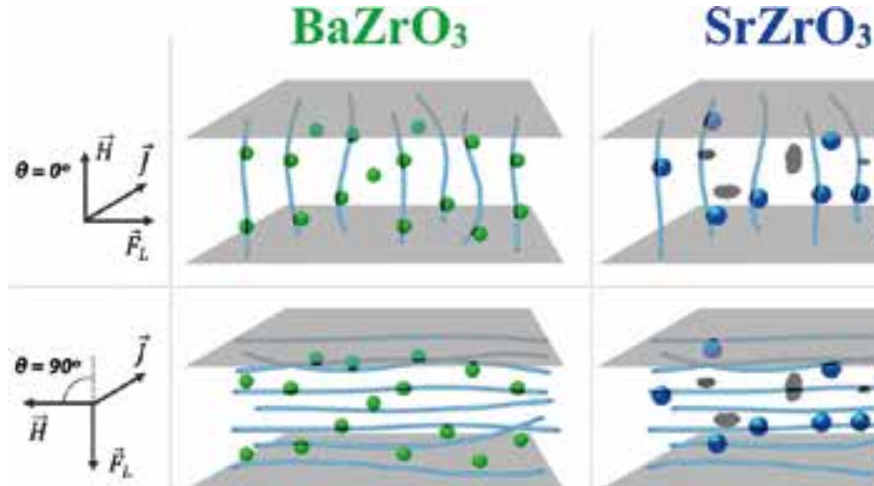
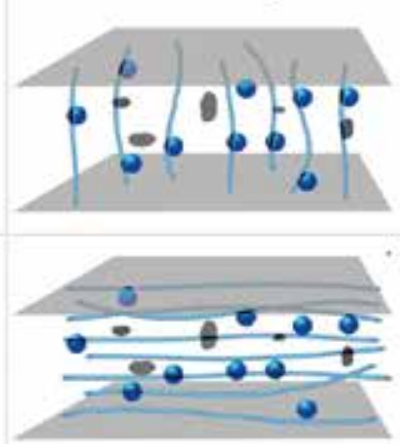

$\mathrm{BaHFO}_{3}$
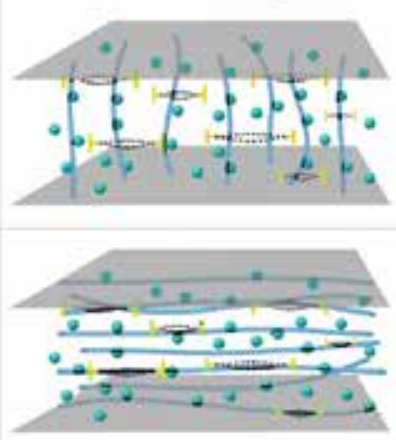

$\mathrm{BaTiO}_{3}$

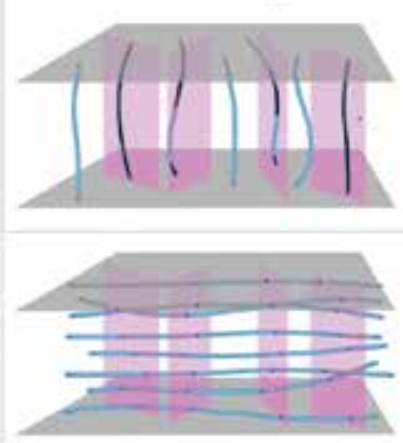

Fig. 9. Schematic illustration of the four nanocomposites showing the main defects present: homogeneously distributed nanocrystals [for BZO (green), SZO (blue), and $\mathrm{BHO}$ (cyan)], intergrowths (for $\mathrm{BHO}$ ), small secondary phases such as $\mathrm{Y}_{2} \mathrm{O}_{3}$ [for SZO (gray)], and highly coherent twin boundaries [for BTO (pink)]. Reprinted with permission from ref. [83]. Copyright 2020 American Chemical Society. 
a 3D network that contains trapped solvent molecules (i.e. water). Water is a solvent that is not removed via supercritical drying as it requires high temperatures and high pressure and becomes highly oxidizing. ${ }^{96]}$ Therefore, water is usually exchanged by alcohols or acetone and then brought into supercritical conditions. The solvent is then removed through gas expansion while preserving the macro/microporous structure of the material. Nanoparticles can be used in aerogels by direct incorporation to traditional metal oxide gel-forming composites, ${ }^{[97]}$ or by being employed as nano building blocks (Fig. 11), in which the NCs self-assemble forming the $3 \mathrm{D}$ aerogel structures. The latter strategy is based on the controlled destabilization of functionalized nanoparticles, leading to higher dimensional structures. ${ }^{[98]}$ Specific examples for $c a .4$ nm MEEAA functionalized $\mathrm{BaTiO}_{3}{ }^{[99]}$ and $\mathrm{Cr}$-doped $\mathrm{SrTiO}_{3}{ }^{[100]}$ have led to the formation of aerogels with a surface area over $300 \mathrm{~m}^{2} / \mathrm{g}$. In both examples highly concentrated solutions $(200$ $\mathrm{mg} / \mathrm{mL}$ ) are destabilized by incorporating water to the ethanolic NCs solutions and inducing gelation either by heat or ultrasonic treatment. The aerogel monolith is then formed by using a supercritical drying approach, which successfully avoids pore collapse. This can be verified by BET measurements, giving information about surface area and pore structure. $\mathrm{BaTiO}_{3}$-based aerogels have been successfully tested regarding their photocatalytic activity in methyl orange degradation. ${ }^{[101]} \mathrm{A}$ more thorough review on inorganic aerogels ${ }^{[102]}$ and the applications in photocatalysis ${ }^{[103]}$ may be found elsewhere.

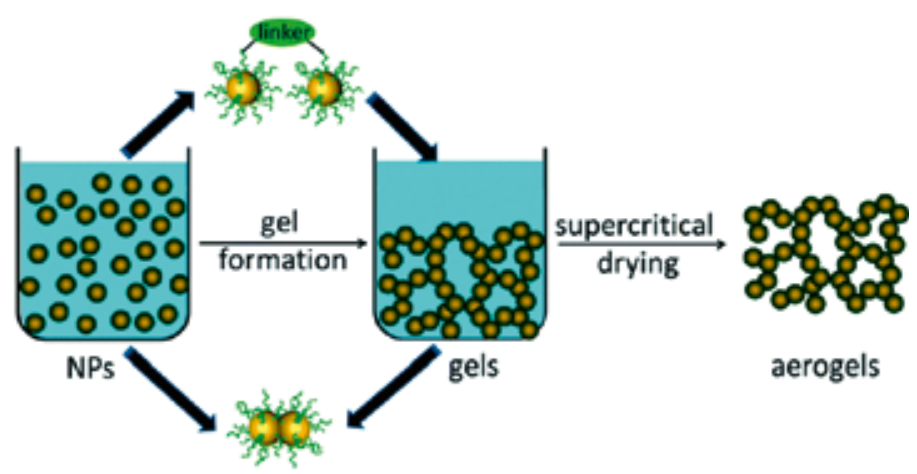

Fig. 11. Schematic illustration of colloidal nanocrystal 3D assembly into aerogels. Reproduced from ref. [104] with permission from The Royal Society of Chemistry.

\section{Summary and Outlook}

The demand for smaller electronic components has driven much of the research in the field of perovskite oxide nanocrystals. The bottom-up approach appears to be the route with the most significant potential due to reduced cost. However, reducing the dimensions to a few nanometers brings new challenges regarding a controlled synthesis, specifically in terms of size and shape. In this review, we have presented the primary synthetic strategies. Most attention has been dedicated to those which were able to prepare sub-10 nm crystals as well as stabilize NCs in solution. All this information has been summarized in Table 1 as a quick-access guide with the most prominent examples. A general synthesis route should be pursued, in which nanocrystal growth is controlled and understood at the nanometer level. The Niederberger group has made significant advances in elucidating the mechanism of solvothermal reactions. At the same time, there are still many unknowns about nanocrystal growth in a vast number of synthetic routes. When NC size becomes key for the applications pursued, controlled precision synthesis is crucial. Techniques able to monitor the progress of the reaction are at an early stage, but they provide essential information for the un- derstanding and design of NCs synthetic routes. We foresee the use of kinetically controlled synthesis and precursor design as a robust strategy for size and shape detailed control, already proven for single oxides or semiconductor nanocrystals. In the second section of this review, the main applications that can take advantage of the stabilized nanocrystal solutions have been reviewed. Flexible electronics keep pushing for innovative energy storage solutions, which translate into new flexible ceramic-polymer composites that can store high energy densities. Superconductors and non-volatile memory devices also benefit from NCs as individual building blocks, improving current performances or promoting new forms of information storage.

\section{Acknowledgements}

The authors acknowledge the funding received from the European Union's Horizon 2020 Research and Innovation Programme under the Marie Skłodowska-Curie Grant agreement No. 722071 (SynFoNY, www.synfony.eu).

\section{ORCID iD}

Pedro López-Domínguez: 0000-0002-8222-6200

Isabel Van Driessche: 0000-0001-5253-3325

\section{Conflicting Interests}

The authors declare no competing financial interest.

[1] J. M. L. Cabello, M. De Las Mercedes Pardo Figuerez, A. C. Flor, Spanish Patent Appl. No. ES2765374A1, 2020

[2] T. Ishihara, in 'Springer Handbook of Electronic and Photonic Materials', Eds. S. Kasap, P. Capper, Springer International Publishing, Cham, 2017, p. 1, https://doi.org/10.1007/978-3-319-48933-9_59.

[3] V. M. Goldschmidt, Naturwissenschaften 1926, 14, 477, https://doi.org/10.1007/BF01507527.

[4] C. J. Bartel, C. Sutton, B. R. Goldsmith, R. Ouyang, C. B. Musgrave, L. M. Ghiringhelli, M. Scheffler, Sci. Adv. 2019, 5, eaav0693, https://doi.org/10.1126/sciadv.aav0693.

[5] S. Ray, Y. V. Kolen'ko, K. A. Kovnir, O. I. Lebedev, S. Turner, T. Chakraborty, R. Erni, T. Watanabe, G. V. Tendeloo, M. Yoshimura, M. Itoh, Nanotechnology 2011, 23, 025702, https://doi.org/10.1088/0957-4484/23/2/025702.

[6] K. Mimura, K. Kato, H. Imai, S. Wada, H. Haneda, M. Kuwabara, Appl. Phys. Lett. 2012, 101, 012901, https://doi.org/10.1063/1.4731198.

[7] R. E. Cohen, Nature 1992, 358, 136, https://doi.org/10.1038/358136a0.

[8] F. A. Pearsall, J. Lombardi, N. Farahmand, B. v. Tassel, E. S. Leland, L. Huang, S. Liu, S. Yang, C. Le, I. Kymissis, P. Kinget, S. R. Sanders, D. Steingart, S. O. Brien, IEEE Trans. Nanotechnol. 2020, 19, 255, https://doi.org/10.1109/TNANO.2019.2939093.

[9] a) P. Cayado, H. Rijckaert, T. Thersleff, M. Erbe, J. Hänisch, I. V. Driessche, B. Holzapfel, IEEE Trans. Appl. Supercond. 2020, 30, 1, https://doi.org/10.1109/TASC.2020.2966429; b) M. K. Wu, J. R. Ashburn, C. J. Torng, P. H. Hor, R. L. Meng, L. Gao, Z. J. Huang, Y. Q. Wang, C. W. Chu, Phys. Rev. Lett. 1987, 58, 908, https://doi.org/10.1103/ PhysRevLett.58.908.

[10] M. Li, M. J. Pietrowski, R. A. De Souza, H. Zhang, I. M. Reaney, S. N. Cook, J. A. Kilner, D. C. Sinclair, Nat. Mater. 2014, 13, 31, https://doi.org/10.1038/nmat3782.

[11] J. Zhu, H. Li, L. Zhong, P. Xiao, X. Xu, X. Yang, Z. Zhao, J. Li, ACS Catal. 2014, 4, 2917, https://doi.org/10.1021/cs500606g.

[12] S. Sengodan, S. Choi, A. Jun, T. H. Shin, Y.-W. Ju, H. Y. Jeong, J. Shin, J. T. S. Irvine, G. Kim, Nat. Mater. 2015, 14, 205, https://doi.org/10.1038/nmat4166.

[13] J. Li, Y. Chen, Y. Yang, N. Kawazoe, G. Chen, J. Mater. Chem. B 2017, 5, 1353, https://doi.org/10.1039/C6TB03276A.

[14] N. Moutalbi, A. Ouerghi, A. M'chirgui, J. Supercond. Novel Magn. 2011, 24, 165, https://doi.org/10.1007/s10948-010-0912-8.

[15] L. Li, J. Yan, T. Wang, Z.-J. Zhao, J. Zhang, J. Gong, N. Guan, Nat. Commun. 2015, 6, 5881, https://doi.org/10.1038/ncomms6881.

[16] C. Ando, R. Yanagawa, H. Chazono, H. Kishi, M. Senna, J. Mater. Res. 2004, 19, 3592, https://doi.org/10.1557/JMR.2004.0461.

[17] a) K. Tsunekawa, Y. Hotta, K. Sato, K. Watari, J. Ceram. Soc. Jpn. 2006, 114, 651, https://doi.org/10.2109/jcersj.114.651; b) J. Peng, T. Peng, L. Zhang, Y. Tang, Chinese Patent Appl. No. CN104828858B, 2015. 
[18] T. Charoonsuk, N. Vittayakorn, Mater. Des. 2016, 110, 233, https://doi.org/10.1016/j.matdes.2016.07.137.

[19] S. H. Feng, G. H. Li, in 'Modern Inorganic Synthetic Chemistry (Second Edition)', Eds. R. Xu, Y. Xu, Elsevier, Amsterdam, 2017, p. 73, https://doi.org/10.1016/B978-0-444-63591-4.00004-5.

[20] A. K. Cheetham, G. Férey, T. Loiseau, Angew. Chem. Int. Ed. 1999, 38, 3268 , https://doi.org/10.1002/(sici)1521-3773(19991115)38:22<3268::aidanie3268>3.0.co;2-u.

[21] O. M. Yaghi, H. Li, C. Davis, D. Richardson, T. L. Groy, Acc. Chem. Res. 1998, 31, 474, https://doi.org/10.1021/ar970151f.

[22] a) Y. V. Kolen'ko, A. A. Burukhin, B. R. Churagulov, N. N. Oleynikov, Mater. Lett. 2003, 57, 1124, https://doi.org/10.1016/S0167577X(02)00943-6; b) C.-S. Kim, B. K. Moon, J.-H. Park, B.-C. Choi, H.J. Seo, J. Cryst. Growth 2003, 257, 309, https://doi.org/10.1016/S00220248(03)01468-4.

[23] a) Christen.An, Acta Chem. Scand. 1970, 24, 2447, https://doi.org/10.3891/ acta.chem.scand.24-2447; b) 正. 金子, 文. 井本, 日本化学会誌(化学と工業 化学 1975, 1975, 985, https://doi.org/10.1246/nikkashi.1975.985.

[24] X. Wang, J. Zhuang, Q. Peng, Y. Li, Nature 2005, 437, 121, https://doi.org/10.1038/nature03968.

[25] S. Adireddy, C. Lin, B. Cao, W. Zhou, G. Caruntu, Chem. Mater. 2010, 22 , 1946, https://doi.org/10.1021/cm9038768.

[26] a) F. Dang, K.-i. Mimura, K. Kato, H. Imai, S. Wada, H. Haneda, M. Kuwabara, CrystEngComm 2011, 13, 3878, https://doi.org/10.1039/C1CE05296A; b) Q. Ma, K.i. Mimura, K. Kato, J. Alloys Compd. 2016, 655, 71, https://doi.org/10.1016/j.jallcom.2015.09.156; $\quad$ c) Ma, K. Kato, Cryst. Growth Des. 2017, 17, 2507, https://doi.org/10.1021/acs.cgd.7b00025;

Q. Ma, K. Kato, Mater. Des. 2016, 107, 378 https://doi.org/10.1016/j.matdes.2016.06.065; e) R. I. Walton, F. Millange, R. I. Smith, T. C. Hansen, D. O'Hare, J. Am. Chem. Soc. 2001 123, 12547, https://doi.org/10.1021/ja011805p

[27] a) M. Niederberger, G. Garnweitner, N. Pinna, M. Antonietti, J. Am. Chem. Soc. 2004, 126, 9120, https://doi.org/10.1021/ja0494959; b) M. Niederberger, N. Pinna, J. Polleux, M. Antonietti, Angew. Chem., Int. Ed. 2004, 43, 2270, https://doi.org/10.1002/anie.200353300.

[28] R. C. Mehrotra, A. Singh, S. Sogani, Chem. Soc. Rev. 1994, 23, 215, https://doi.org/10.1039/CS9942300215.

[29] A. Vioux, Chem. Mater. 1997, 9, 2292, https://doi.org/10.1021/ cm970322a.

[30] a) K. Nakashima, M. Kera, I. Fujii, S. Wada, Ceram. Int. 2013, 39 , 3231, https://doi.org/10.1016/j.ceramint.2012.10.009; b) L. Huang, Z. Jia, I. Kymissis, S. O'Brien, Adv. Funct. Mater. 2010, 20, 554, https://doi.org/10.1002/adfm.200901258.

[31] a) H. T. Pham, J. H. Yang, D.-S. Lee, B. H. Lee, H.-D. Jeong, ACS Appl. Mater. Interfaces 2016, 8, 7248, https://doi.org/10.1021/acsami.6b00109; b) Y. V. Kolen'ko, K. A. Kovnir, I. S. Neira, T. Taniguchi, T. Ishigaki, T. Watanabe, N. Sakamoto, M. Yoshimura, J. Phys. Chem. C 2007, 111, 7306, https://doi.org/10.1021/jp0678103.

[32] J. Zhou, Z. Yang, CrystEngComm 2013, 15, 8912, https://doi.org/10.1039/C3CE41549J.

[33] D. Caruntu, T. Rostamzadeh, T. Costanzo, S. Salemizadeh Parizi, G. Caruntu, Nanoscale 2015, 7, 12955, https://doi.org/10.1039/ C5NR00737B.

[34] H. Du, S. Wohlrab, M. Weiß, S. Kaskel, J. Mater. Chem. 2007, 17, 4605, https://doi.org/10.1039/B708914G.

[35] a) H. Du, C.-L. Jia, J. Mayer, Chem. Mater. 2016, 28, 650, https://doi.org/10.1021/acs.chemmater.5b04486; b) C. Friderichs, N. Zotov, W. Mader, Eur. J. Inorg. Chem. 2015, 2015, 288, https://doi.org/10.1002/ejic.201402724

[36] T. Costanzo, J. McCracken, A. Rotaru, G. Caruntu, ACS Appl. Nano Mater. 2018, 1, 4863, https://doi.org/10.1021/acsanm.8b01036.

[37] Y. Hao, X. Wang, J. Kim, L. Li, J. Am. Ceram. Soc. 2014, 97, 3434 https://doi.org/10.1111/jace.13153.

[38] Z. He, Y. Hao, M. Bi, L. Guo, K. Bi, Micro Nano Lett. 2019, 14, 289, https://doi.org/10.1049/mnl.2018.5559.

[39] Y. Hao, X. Wang, L. Li, Nanoscale 2014, 6, 7940, https://doi.org/10.1039/C4NR00171K.

[40] R. L. Brutchey, D. E. Morse, Angew. Chem., Int. Ed. 2006, 45, 6564, https://doi.org/10.1002/anie.200602571.

[41] C. W. Beier, M. A. Cuevas, R. L. Brutchey, J. Mater. Chem. 2010, 20, 5074, https://doi.org/10.1039/C0JM00845A.

[42] F. A. Rabuffetti, R. L. Brutchey, Chem. Commun. 2012, 48, 1437, https://doi.org/10.1039/C1CC14166J.

[43] F. A. Rabuffetti, R. L. Brutchey, Dalton Trans. 2014, 43, 14499, https://doi.org/10.1039/C4DT01376J.

[44] C. W. Beier, M. A. Cuevas, R. L. Brutchey, Langmuir 2010, 26, 5067, https://doi.org/10.1021/la9035419.

[45] R. L. Brutchey, G. Cheng, Q. Gu, D. E. Morse, Adv. Mater. 2008, 20 , 1029, https://doi.org/10.1002/adma.200701804.
[46] F. A. Rabuffetti, J. S. Lee, R. L. Brutchey, Adv. Mater. 2012, 24, 1434, https://doi.org/10.1002/adma.201104645.

[47] S. O'Brien, L. Brus, C. B. Murray, J. Am. Chem. Soc. 2001, 123, 12085 , https://doi.org/10.1021/ja011414a.

[48] V. W. Day, T. A. Eberspacher, M. H. Frey, W. G. Klemperer, S. Liang, D. A Payne, Chem. Mater. 1996, 8, 330, https://doi.org/10.1021/cm950547q.

[49] Q. J. Cai, Y. Gan, M. B. Chan-Park, H. B. Yang, Z. S. Lu, C. M. Li, J. Guo, Z. L. Dong, Chem. Mater. 2009, 21, 3153, https://doi.org/10.1021/cm900532q.

[50] Z. Chen, L. Huang, J. He, Y. Zhu, S. O'Brien, J. Mater. Res. 2006, 21, 3187 , https://doi.org/10.1557/jmr.2006.0389.

[51] S. Liu, L. Huang, W. Li, X. Liu, S. Jing, J. Li, S. O'Brien, Nanoscale 2015 7, 11766, https://doi.org/10.1039/C5NR02351C

[52] J. Lombardi, L. Yang, F. A. Pearsall, N. Farahmand, Z. Gai, S. J. L. Billinge, S. O'Brien, Chem. Mater. 2019, 31, 1318, https://doi.org/10.1021/acs.chemmater.8b04447.

[53] H. Herrig, R. Hempelmann, Mater. Lett. 1996, 27, 287 , https://doi.org/10.1016/0167-577X(96)00011-0.

[54] K. Su, N. Nuraje, N.-L. Yang, Langmuir 2007, 23, 11369 , https://doi.org/10.1021/la701877d.

[55] Z. Deng, Y. Dai, H. Xiao, M. J. Zhou, Adv. Mat. Res. 2014, 1004-1005, 63 , https://doi.org/10.4028/www.scientific.net/AMR.1004-1005.63.

[56] P. López-Domínguez, A. M. López-Periago, F. J. Fernández-Porras, J. Fraile, G. Tobias, C. Domingo, J. CO2 Util. 2017, 18, 147, https://doi.org/10.1016/j.jcou.2017.01.019.

[57] F. Bocquet, K. Chhor, C. Pommier, Mater. Chem. Phys. 1999, 57, 273 , https://doi.org/10.1016/S0254-0584(98)00233-8.

[58] G. Philippot, M. Albino, U. C. Chung, M. Josse, C. Elissalde, M. Maglione, C. Aymonier, Mater. Des. 2015, 86, 354 https://doi.org/10.1016/j.matdes.2015.07.111.

[59] G. Philippot, E. D. Boejesen, C. Elissalde, M. Maglione, C. Aymonier, B. B. Iversen, Chem. Mater. 2016, 28, 3391, https://doi.org/10.1021/acs.chemmater.6b00635.

[60] a) V. LaMer, R. Dinegar, J. Am. Chem. Soc. 1950, 72, 4847, https://doi org/10.1021/ja01167a001; b) T.-D. Nguyen, T.-D. Do, in 'Nanocrystal', Eds. Y. Masuda, Intech, 2011, p. 55-84, https://doi.org/10.5772/17054.

[61] V. Bansal, P. Poddar, A. Ahmad, M. Sastry, J. Am. Chem. Soc. 2006, 128, 11958, https://doi.org/10.1021/ja063011m.

[62] N. Nuraje, K. Su, A. Haboosheh, J. Samson, E. P. Manning, N.-1. Yang, H. Matsui, Adv. Mater. 2006, 18, 807, https://doi.org/10.1002/adma.200501340.

[63] A. K. Jha, K. Prasad, Integr. Ferroelectr. 2010, 117, 49, https://doi.org/10.1080/10584587.2010.489422.

[64] a) V. Bansal, D. Rautaray, A. Bharde, K. Ahire, A. Sanyal, A. Ahmad, M. Sastry J. Mater. Chem. 2005, 15, 2583, https://doi.org/10.1039/B503008K; b) V. Bansal, A. Sanyal, D. Rautaray, A. Ahmad, M. Sastry, Adv. Mater 2005, 17, 889, https://doi.org/10.1002/adma.200401176.

[65] V. Bansal, D. Rautaray, A. Ahmad, M. Sastry, J. Mater. Chem. 2004, 14, 3303, https://doi.org/10.1039/B407904C.

[66] A. Bharde, D. Rautaray, V. Bansal, A. Ahmad, I. Sarkar, S. M. Yusuf, M. Sanyal, M. Sastry, Small 2006, 2, 135 , https://doi.org/10.1002/smll.200500180.

[67] C. H. Ahn, K. M. Rabe, J. M. Triscone, Science 2004, 303, 488, https://doi.org/10.1126/science.1092508.

[68] M. E. Villafuerte-Castrejón, E. Morán, A. Reyes-Montero, R. VivarOcampo, J.-A. Peña-Jiménez, S.-O. Rea-López, L. Pardo, Materials 2016, 9, 21, https://doi.org/10.3390/ma9010021.

[69] L. Huang, Z. Chen, J. D. Wilson, S. Banerjee, R. D. Robinson, I. P. Herman, R. Laibowitz, S. O'Brien, J. Appl. Phys. 2006, 100, 034316, https://doi.org/10.1063/1.2218765.

[70] C. Liu, B. Zou, A. J. Rondinone, Z. J. Zhang, J. Am. Chem. Soc. 2001, 123, 4344, https://doi.org/10.1021/ja001893y.

[71] a) J. G. Barbosa, M. R. Pereira, C. Moura, J. A. Mendes, B. G. Almeida, J. Nanosci. Nanotechnol. 2011, 11, 8700 https://doi.org/10.1166/jnn.2011.3494; b) F. Nakasone, K. Kobayashi, T. Suzuki, Y. Mizuno, H. Chazono, H. Imai, Jpn. J. Appl. Phys. 2008, 47, 8518, https://doi.org/10.1143/jjap.47.8518; c) Y. J. Wu, J. Li, H. Tanaka, M. Kuwabara, J. Eur. Ceram. Soc. 2005, 25, 2041, https://doi.org/10.1016/j.jeurceramsoc.2005.03.008.

[72] H. Yaseen, S. Baltianski, Y. Tsur, J. Mater. Sci. 2007, 42, 9679 , https://doi.org/10.1007/s10853-007-1944-8.

[73] Q. Wang, L. Zhu, J. Polym. Sci., Part B: Polym. Phys. 2011, 49, 1421, https://doi.org/0.1002/polb.22337.

[74] a) S. S. Parizi, G. Conley, T. Costanzo, B. Howell, A. Mellinger, G. Caruntu, RSC Advances 2015, 5, 76356, https://doi.org/10.1039/C5RA11347D b) D. Caruntu, B. Kavey, S. Paul, A. C. Bas, A. Rotaru, G. Caruntu, CrystEngComm 2020, 22, 1261, https://doi.org/10.1039/C9CE01912J.

[75] S. S. Parizi, A. Mellinger, G. Caruntu, ACS Appl. Mater. Interfaces 2014, 6, 17506, https://doi.org/10.1021/am502547h.

[76] A. Dong, X. Ye, J. Chen, Y. Kang, T. Gordon, J. M. Kikkawa, C. B. Murray, J. Am. Chem. Soc. 2011, 133, 998, https://doi.org/10.1021/ja108948z. 
[77] Y. Hao, X. Wang, K. Bi, J. Zhang, Y. Huang, L. Wu, P. Zhao, K. Xu, M. Lei, L. Li, Nano Energy 2017, 31, 49, https://doi.org/10.1016/j.nanoen.2016.11.008

[78] a) H. Rijckaert, P. Cayado, R. Nast, J. Diez Sierra, M. Erbe, P. López Domínguez, J. Hänisch, K. De Buysser, B. Holzapfel, I. Van Driessche, Coatings 2020, 10, 17, https://doi.org/10.3390/coatings10010017; b) K. Iida, P. Cayado, H. Rijckaert, M. Erbe, J. Hänisch, T. Okada, I. Van Driessche, S. Awaji, B. Holzapfel, Supercond. Sci. Technol. 2020, 34, 015009, https://doi.org/10.1088/1361-6668/abb205.

[79] X. Obradors, T. Puig, Z. Li, C. Pop, B. Mundet, N. Chamorro, F. Vallés, M. Coll, S. Ricart, B. Vallejo, F. Pino, A. Palau, J. Gázquez, J. Ros, A. Usoskin, Supercond. Sci. Technol. 2018, 31, 044001, https://doi.org/10.1088/13616668/aaaad7.

[80] F. Martínez-Julián, S. Ricart, A. Pomar, M. Coll, P. Abellán, F. Sandiumenge, M. J. Casanove, X. Obradors, T. Puig, I. PastorizaSantos, L. M. Liz-Marzán, J. Nanosci. Nanotechnol. 2011, 11, 3245, https://doi.org/10.1166/jnn.2011.3762.

[81] a) H. Rijckaert, G. Pollefeyt, M. Sieger, J. Hänisch, J. Bennewitz, K. De Keukeleere, J. De Roo, R. Hühne, M. Bäcker, P. Paturi, H. Huhtinen, M. Hemgesberg, I. Van Driessche, Chem. Mater. 2017, 29, 6104, https://doi.org/10.1021/acs.chemmater.7b02116; b) H. Rijckaert, J. De Roo, M. Van Zele, S. Banerjee, H. Huhtinen, P. Paturi, J. Bennewitz, S. J. L. Billinge, M. Bäcker, K. De Buysser, I. Van Driessche, Materials 2018, 11, 1066, https://doi.org/10.3390/ma11071066.

[82] Z. Li, M. Coll, B. Mundet, N. Chamorro, F. Vallès, A. Palau, J. Gazquez, S. Ricart, T. Puig, X. Obradors, Sci. Rep. 2019, 9, 5828, https://doi.org/10.1038/s41598-019-42291-x.

[83] J. Díez-Sierra, P. López-Domínguez, H. Rijckaert, M. Rikel, J. Hänisch, M. Z. Khan, M. Falter, J. Bennewitz, H. Huhtinen, S. Schäfer, R. Müller, S. A. Schunk, P. Paturi, M. Bäcker, K. De Buysser, I. Van Driessche, ACS Appl. Nano Mater. 2020, 3, 5542, https://doi.org/10.1021/acsanm.0c00814.

[84] a) R. Waser, M. Aono, Nat. Mater. 2007, 6, 833, https://doi.org/10.1038/nmat2023; b) A. Sawa, Mater. Today 2008, 11, 28, https://doi.org/10.1016/S1369-7021(08)70119-6.

[85] J. J. Yang, M. D. Pickett, X. Li, D. A. A. Ohlberg, D. R. Stewart, R. S. Williams, Nat. Nanotechnol. 2008, 3, 429, https://doi.org/10.1038/nnano.2008.160.

[86] J. Wang, S. Choudhary, W. L. Harrigan, A. J. Crosby, K. R. Kittilstved, S. S. Nonnenmann, ACS Appl. Mater. Interfaces 2017, 9, 10847, https://doi.org/10.1021/acsami.7b00220.

[87] Z. Zhou, P. López-Domínguez, M. Abdullah, D. Barber, X. Meng, I Van Driessche, J. Schiffman, K. Kittilstved, A. Crosby, J. De Roo, S. S. Nonnenmann, 2021, submitted.

[88] a) J. De Roo, Z. Zhou, J. Wang, L. Deblock, A. J. Crosby, J. S. Owen, S. S. Nonnenmann, Chem. Mater. 2018, 30, 8034, https://doi.org/10.1021/acs.chemmater.8b03768; b) J. Wang, S. Choudhary, J. De Roo, K. De Keukeleere, I. Van Driessche, A. J. Crosby, S. S. Nonnenmann, ACS Appl. Mater. Interfaces 2018, 10, 4824, https://doi.org/10.1021/acsami.7b17376.

[89] H. D. Gesser, P. C. Goswami, Chem. Rev. 1989, 89, 765, https://doi.org/10.1021/cr00094a003.

[90] a) X. Mi, G. Huang, W. Xie, W. Wang, Y. Liu, J. Gao, Carbon 2012, 50, 4856, https://doi.org/10.1016/j.carbon.2012.06.013; b) Z. Tong, D. Yang, J.
Shi, Y. Nan, Y. Sun, Z. Jiang, ACS Appl. Mater. Interfaces 2015, 7, 25693, https://doi.org/10.1021/acsami.5b09503.

[91] a) R. W. Pekala, J. Mater. Sci. 1989, 24, 3221 https://doi.org/10.1007/BF01139044; b) Z.-S. Wu, S. Yang, Y. Sun, K. Parvez, X. Feng, K. Müllen, J. Am. Chem. Soc. 2012, 134, 9082, https://doi.org/10.1021/ja3030565.

[92] A. K. Meena, G. K. Mishra, P. K. Rai, C. Rajagopal, P. N. Nagar, J. Hazard. Mater. 2005, 122, 161, https://doi.org/10.1016/j.jhazmat.2005.03.024.

[93] a) I. Smirnova, P. Gurikov, Annu. Rev. Chem. Biomol. Eng. 2017, 8, 307, https://doi.org/10.1146/annurev-chembioeng-060816-101458; b) Z. Li, S. Zhao, M. M. Koebel, W. J. Malfait, Mater. Des. 2020, 193, 108833 https://doi.org/10.1016/j.matdes.2020.108833.

[94] S. S. Kistler, Nature 1931, 127, 741, https://doi.org/10.1038/127741a0.

[95] A. C. Pierre, G. M. Pajonk, Chem. Rev. 2002, 102, 4243, https://doi.org/10.1021/cr0101306.

[96] M. D. Bermejo, M. J. Cocero, AIChE J. 2006, 52, 3933, https://doi.org/10.1002/aic.10993.

[97] W. Chen, S. Li, C. Chen, L. Yan, Adv. Mater. 2011, 23, 5679, https://doi.org/10.1002/adma.201102838.

[98] a) J. Polleux, N. Pinna, M. Antonietti, M. Niederberger, Adv. Mater. 2004, 16, 436, https://doi.org/10.1002/adma.200306251; b) J. Polleux, N. Pinna, M. Antonietti, C. Hess, U. Wild, R. Schlögl, M. Niederberger, Chem. - Eur. J. 2005, 11, 3541, https://doi.org/10.1002/chem.200401050.

[99] F. Rechberger, F. J. Heiligtag, M. J. Süess, M. Niederberger, Angew. Chem., Int. Ed. 2014, 53, 6823, https://doi.org/10.1002/anie.201402164.

[100] F. Rechberger, G. Ilari, C. Willa, E. Tervoort, M. Niederberger, Mater. Chem. Front. 2017, 1, 1662, https://doi.org/10.1039/C7QM00155J.

[101] Y. Li, J. Wu, X. Wu, H. Suo, X. Shen, S. Cui, J. Sol-Gel Sci. Technol. 2019 90, 313, https://doi.org/10.1007/s10971-019-04948-x.

[102] C. Ziegler, A. Wolf, W. Liu, A.-K. Herrmann, N. Gaponik, A. Eychmüller, Angew. Chem., Int. Ed. 2017, 56, 13200, https://doi.org/10.1002/anie.201611552.

[103] W. Wan, R. Zhang, M. Ma, Y. Zhou, J. Mater. Chem. A 2018, 6, 754 https://doi.org/10.1039/C7TA09227J.

[104] D. Wen, A. Eychmüller, Chem. Commun. 2017, 53, 12608, https://doi.org/10.1039/C7CC03862C

[105] D. Taroata, W. Fischer, T. A. Cheema, G. Garnweitner, G. Schmid, IEEE Trans. Dielectr. Electr. Insul. 2012, 19, 298, Spanish Patent Appl. No. ES2765374A1, 202010.1109/TDEI.2012.6148531.

\section{License and Terms}

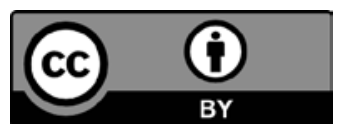

This is an Open Access article under the terms of the Creative Commons Attribution License CC BY 4.0. The material may not be used for commercial purposes.

The license is subject to the CHIMIA terms and conditions: (http:// chimia.ch/component/sppagebuilder/?view=page \&id=12).

The definitive version of this article is the electronic one that can be found at https://doi.org/10.2533/chimia.2021.376 